\title{
Evaluation of Equivalent Structural Properties of NREL Phase VI Wind Turbine Blade
}

\author{
Kyoungsoo Lee ${ }^{1} \quad$ Ziaul Huque $^{1,2}$ Raghava Kommalapati ${ }^{1,3} \quad$ Sang-Eul Han $^{4}$ \\ ${ }^{1}$ Center for Energy and Environmental Sustainability (CEES), Prairie View A\&M University: kylee@pvamu.edu \\ ${ }^{2}$ Department of Mechanical Engineering, Prairie View A\&M University: zihuque@pvamu.edu \\ ${ }^{3}$ Department of Civil \& Environmental Engineering, Prairie View A\&M University: rrkommalapati@pvamu.edu \\ 1,2,3 Prairie View A\&M University, Prairie View, Texas 77446 \\ ${ }^{4}$ School of Architecture, Department of Architectural Engineering, Inha University, Inchoen, Korea 402-751 : \\ hsang@inha.ac.kr \\ * Correspondence to Dr. Lee (kylee@pvamu.edu), Tel: 1-936-261-9957
}

\begin{abstract}
This paper presents the structural model development and verification process for the National Renewable Energy Laboratory (NREL) Phase VI wind which consists of the blades, rotor, nacelle, and tower. The mass and stiffness properties of all parts had to be clearly defined to develop the structural model for the entire turbine. However, it was difficult to define the geometries and material properties of the blade structure and power generating machinery because of their complexity. To perform a FSI analysis, fluid and structural models that shared the associated interface topology had to be provided. With the help of an eigen-value analysis, the structural stiffness and mass properties were verified in comparison with the values reported by NREL. A finite element (FE) model that included the blade, nacelle, and tower was developed based on the NREL's reported data. The commercial FE software ANSYS was used to develop the geometry and mesh, and to perform the eigen-value analysis. The various material properties and configurations of the entire turbine system were tested to obtain the proper material properties to determine this value. Overall, the proposed geometry, material, and mass properties were in good agreement with the measurements, but need to be discussed further.
\end{abstract}

Keyword: National Renewable Energy Laboratory Phase VI wind turbine blade; structural model; finite element; eigen-value analysis; natural frequency; fluid-structure interaction; 


\section{Introduction}

2 Wind energy is an unlimited renewable energy resource that can substitute for fossil energy. The energy problems we are facing today center around two main drivers: supply and greenhouse gas emissions. Renewable energy sources are an inevitable part of the solutions. Wind energy is undoubtedly one of the cleanest forms of power from a renewable source. As a new type of renewable energy, wind power is being increasingly used and is currently the fastest growing installed production technology. In order for wind energy to be a viable alternate energy source and compete with fossil fuels, it is extremely important to optimize the aerodynamic force of a wind turbine blade by using the appropriate materials for its construction.

A wind turbine blade is designed with a complex three-dimensional (3D) shape using integrated two-dimensional (2D) airfoils to optimize the aerodynamic force efficiency. Accurately evaluating the aerodynamic force and loading on the wind blade structure is not simple but requires comprehensive work. The blade's material is not usually homogeneous but an anisotropic composite material that uses glass fiber reinforced polymer. Because it is difficult to determine a blade's sectional stiffness and material properties analytically, a measurement method is commonly used.

A wind tunnel [1-4] test can be regarded as the most accurate and efficient method to determine the aerodynamic force of a wind turbine blade. However, this method is not available to every researcher and engineer who needs design information about a new blade shape. There are only a few facilities that can perform a full-scale wind tunnel test $[3,4]$. The blade element momentum (BEM) theory [5-10] is successfully used to design wind turbine blades. When used along with wind tunnel test data, the aerodynamic force coefficients from an experiment can be converted into the global torque and thrust force. In the BEM approach, a 3D finite element (FE) model of the blade section cannot be applied explicitly, but the measured sectional and material properties are 
used for one-dimensional (1D) blade element $[5,6,7,10]$. This method makes it easy and efficient to evaluate the aerodynamic force on a blade surface, and the simplified integrating equation of the BEM is easy to incorporate with the FE code.

To increase the accuracy of the BEM by considering the rotating effects of a wind blade, a more accurate 3D FE analysis [8,9] and 3D wind tunnel test should be performed. However, even when using 3D wind tunnel test data, the evaluated aerodynamic forces have discontinuity along the span and chord-wise length. This is because, in the wind tunnel test, the pressure tabs cannot be placed with sufficient accuracy on the $3 \mathrm{D}$ curved wind blade surface. There is a limitation when placing the pressure tabs. The measured aerodynamic forces can be highly affected by the blade surface shape and pressure tab locations. To obtain a more accurate aerodynamic force and apply it to the wind blade surface continuously and accurately, a continuous domain-based fluid-structure interaction (FSI) method [11,12] can be used, in which the well-developed computational fluid dynamics (CFD) and finite element method (FEM) can be combined through a shared interface defined by the topological surface.

To analyze the air flow around a wind blade and evaluate the aerodynamic force, the CFD method has been successfully studied, and its accuracy and applicability to the NREL Phase VI wind turbine blade was demonstrated [13-19] successfully. To obtain the blade's sectional aerodynamic force, the blade pressure distribution was analyzed, and it was converted to sectional aerodynamic force quantities to verify the accuracies of CFD analysis. This did not require any pressure tabs. Hence, continuous results could be obtained on the blade surface. However, to take into account the realistic inflow turbulence in inlet boundary and to verify the analyzed results, it is necessary to use the wind tunnel test data. Moreover, even though steady state Reynolds-averaged Navier-Stokes equations (RANS) CFD analysis, the higher computing cost is not avoidable. Nevertheless there are 
still limitations when using CFD, this method has potential advantages over a wind tunnel test when evaluating the surface pressure distribution.

Other studies have analyzed the structural response of a wind blade using the BEM in combination with an FEM [8,9]. However, these omitted the tower and nacelle, and only considered the composite wind blade and discontinuous aerodynamic force. More accurate FSI studies have also been performed [11-12]. The arbitrary Lagrangian-Eulerian (ALE) formulation was developed for the FSI coupling process. However, similar to those studies that used the BEM and FEM, the tower and nacelle were omitted because of modeling difficulties.

NREL developed the Phase VI wind turbine prototype [3,4] using a S809 airfoil [1,2] and tested its unsteady characteristics. The wind tunnel test data and structural specifications of the entire turbine (blade, tower, and nacelle) are publicly available from the reports [3,4]. Many studies have been published showing and verifying the CFD fluid flow results. However, despite their importance in the turbine design methodology, the structural performance and characteristics have not yet been clearly reported because of the complexity and difficulty of modeling the entire wind turbine system, including the blade, tower, and nacelle. There are many uncertainties in defining the mechanical part of the nacelle. There are also a few nonlinearities associated with the blade's sectional properties. A simplified one-dimensional beam element cannot sufficiently take into account the shell stress and strain distribution $[5,6,7,10]$. Moreover, the tower is the primary structural system supporting the nacelle and blade. Considering the global structural characteristics of the entire turbine system, the blade's stiffness and mass have little importance and may not govern the structural response.

A full scale FE model of NREL Phase VI wind turbine can be verified by comparing with NREL's 
measured structural data which are mainly vibrating frequencies. The frequencies of blade, whole turbine, turbine without blades and tower alone models were reported with comprehensive material properties of stiffness and mass for each parties. The accuracy of proposing structural FE model can be easily verified. In developing the full scale FE model, the whole turbine system which including the tower should be considered to account the important and governing tower behaviors. The simplified wind turbine model, which omitted the tower and nacelle, may present the limited structural behavior of wind blade along [5-11]. If a verified full scale wind turbine structural model was developed, it can be used for structural analysis along with aerodynamic force evaluations. The wind turbine blade has complex aerodynamic characteristics. To take into account the aerodynamic force in structural analysis, FSI or BEM methods can be applied which are direct and in-direct method of accounting the aerodynamic force of wind blade. The well studies steady or unsteady CFD analysis can be used to get the blade surface pressure information which is integrated to calculate the sectional global aerodynamic forces for static or dynamic analysis cases. Actually, the aerodynamic force evaluation processes are not necessary for FSI analysis fundamentally. Because the surface pressure information in fluid domain is converted into the structural pressure load during FSI process. Fig. 1 briefly illustrates the static structural analysis of NREL Phase VI wind turbine, which was developed in this study, for 1-way FSI and BEM processes. To perform the structural analysis, the accuracy of structural FE model should be tested before analysis.

Therefore, this paper deals with the development and verification of the structural FE model of the entire NREL Phase VI wind turbine system that includes the blade, nacelle, and tower, which were based on the data reported by NREL $[3,4]$ for structural analysis of FSI or BEM analysis. The eigen-value analyses were performed for the blade and the entire system, which had various material properties, azimuth angles, and configurations, to verify the accuracy of the developed FE model. Various parametric studies were performed to get the valid material properties and mesh conditions in comparison with NREL's reported eigen-frequencies. The commercial FE software 
1 ANSYS was used throughout the study. Finally, the validity of the proposed FE model in relation to 2 the FSI or BEM was further discussed.

\section{NREL Phase VI wind turbine blade}

It has been shown that wind turbines undergo complex aerodynamic response phenomena when operating in the field. Field-testing has shown that $3 \mathrm{D}$ effects are prevalent in wind turbine field operation, and wind turbines are subjected to severe dynamic loading conditions from the turbulent inflow and shear across the rotor plane. However, the wind turbine design codes are based on 2D airfoil aerodynamic forces derived from wind tunnel tests using the BEM process. NREL has conducted tests of 3D full-scale, horizontal-axis wind turbines (HAWT) using the Phase VI wind turbine to quantify the information about the 3D aerodynamic behavior [3,4]. NREL's Phase VI wind turbine has full-span pitch control and a power rating of $20 \mathrm{~kW}$. The wind tunnel experiments were performed in NASA's Ames Research Center in 1999 and are considered to be a benchmark for the evaluation of wind turbine aerodynamic codes and grid topologies. A wide range of experimental measurements were reported for the blade surface pressures, integrated aerodynamic forces, shaft torque and thrust, blade root strain, tip acceleration, and wake for $5 \mathrm{~m} / \mathrm{s}$ to $25 \mathrm{~m} / \mathrm{s}$ wind speed cases. This turbine uses two blades with a hub height of $12.2 \mathrm{~m}$ and a rotor diameter of $10.058 \mathrm{~m}$. The linearly tapered and nonlinearly twisted blade profile uses a S809 airfoil shape [1,2]. Detailed information about the structural geometries, mechanical and material properties, and experimental results and procedures can be found in the NREL report $[3,4]$. In addition to numerous aerodynamic measurement parameters, a large quantity of structural information was available to prepare the fluid and structural models.

The structural geometries are shown in Fig. 2. The wind turbine was placed on a semi-span mount 
that was supported by a T-frame and balance frame. The nacelle and blade were supported by a tower, which had a dual steel pipe profile (bottom: @609.6×17.5t (mm), top: @ $406.4 \times 21.4 \mathrm{t}(\mathrm{mm})$ ). Fig. 3 illustrates the details of the blade. The blade was manufactured of composite materials. Fig. 3 (a) shows the S809 airfoil section with sectional pressure tabs which uses a carbon fiber D-spar and an aramid honeycomb for the loading and trailing edges, respectively. The instrumentation wires are carried by a PVC pipe, and the blade pressure transducers are included. The carbon fiber D-spar, which is placed at the middle to leading edge, carries the load. It tapers in thickness from the root to tip. The carbon is primarily unidirectional, with $\pm 45^{\circ}$ S-glass interwoven fiber. The non-loadcarrying skin is made of fiberglass [3]. The locations of the pressure tabs along the surface are illustrated in Fig. 3 (b). The pressure tabs were placed at locations equivalent to $30.0 \%, 46.7 \%$, $63.3 \%, 80.0 \%$, and $95.0 \%$ of the span. In this study, 16 sections were used to develop the taper and twist of the blade surface. Fig. 3 (c) shows the pitch and twist of these 16 sections. The pitch and twist axis was assigned on a $30 \%$ of chord. The $\mathrm{X}$ and $\mathrm{Y}$ axes were positive toward the leading edge (direction of rotation) and out-of-plane (positive downwind), respectively. Fig. 3 (d) shows the isometric view of the developed blade surface geometry that was used to develop the blade structure. Fig. 3 (e) and (f) shows the nonlinear twist angle and linear taper value, respectively. The blade properties were computed using the estimated mass and stiffness distributions, which were found using an experimental code [3]. However more detailed information about the blade and root section thickness distributions along the chord and span was not available. A comparison verifying the predicted and measured blade frequencies has not been conducted by NREL, because of the complex geometry and boundary condition of the pitch shaft [3].

\section{FE model development}

To investigate the comprehensive structural response, a detailed FE model is necessary. The one- 
1 dimensional beam element that is used in BEM is a good choice but has limitations. It cannot define

2 the geometry of a 3D curved blade surface, upon which the stress and strain may be distributed. A

3 composite blade's sectional properties are not easy to determine. An accurate FE model can

4 increase the accuracy of the analysis. However, there are many uncertainties and complexities in the

5 FE model for an entire wind turbine system. A wind turbine can be regarded as a hybrid system that

6 combines a structure and machine. It contains numerous structural and mechanical parts. The blade

7 and tower can be regarded as structural parts. The nacelle, shaft, instrumentation, and power

8 generator can be regarded as mechanical parts. If we investigate the structural characteristic of the

9 mechanical parts, these can be simply understood as a rigid body system with mass. The mechanical

10 parts are located in the hub and nacelle, and include the shaft and generator. Their stress and strain

11 are not significant and important rather than those of the blade or tower. A flexible blade has a high

12 stiffness and low mass. The governing structural stability and response are highly dependent on the

13 tower. The geometry and material properties of the tower are very simple compared with those of 14 the blade and mechanical parts. It can be easily understood as a kind of simple column. The nacelle 15 and rotor, which includes the blade, hub, and shaft, are supported by the tower. The mechanical 16 parts on top of the tower have higher stiffness and mass. Thus, care must be taken to accurately 17 evaluate the properties of mechanical parts. As previously explained, the stiffness and mass 18 distributions of the tower are usually simple, but the 3D curved wind blade has a complex surface 19 and sectional shape. Thus, its structural stiffness and mass distribution have to be determined by 20 measurements [3].

For the NREL Phase VI wind turbine, sufficient information about the wind blade and tower is available to develop the FE model, but not about the mechanical parts. There are many unknowns and complexities [3]. Therefore, in this study, the geometries of the hub, shaft, and mechanical parts of the rotor and nacelle were assumed to be elastic or rigid in the entire turbine system within an 
acceptable range. However, the exact masses of these parts were applied to the FE model by point mass based on the data from NREL $[3,4]$. The quantities of mechanical mass play important roles in the entire turbine system. The higher mass on the top of the tower has significant effects on the vibrating structural response. Fig. 4 illustrates the FE geometries used in this study for the rotor, shaft, and nacelle based on the information from NREL. We omitted the boom, instrumentation enclosures, camera, detailed connections, and some mechanical parts to simplify the FE model, because these were not important for the stiffness, but kept the mass values. The hub, pitch shaft, shaft, and rigid links were included in the FE model.

Fig. 5 explains the overall geometry and masses of the entire turbine system. Table-1 lists the assumed stiffness (material properties) and mass definitions for case 1, case 2, and case 3. To investigate the assumed stiffness properties for uncertain blade and mechanical parts, we tested three material property cases for the blade and mechanical parts with identical mass definitions. Young's elastic modulus for case 2 was different from those of the other cases for the blade material property to test the effective stiffness of the blade; the values for case 1 and case 3 were identical. Elastic and rigid materials were assumed for the mechanical parts (nacelle, hub, shafts) for each case. As a result, case 1 had the lowest blade stiffness and elasticity for the mechanical parts, which resulted in the lowest stiffness overall. Case 2 had a higher blade stiffness and rigid mechanical parts, which resulted in the highest stiffness overall. For case 3, the stiffness definitions were identical to those of case 1, except for the mechanical parts, which were defined as a rigid material like case 2 . The result was an intermediate stiffness overall.

The mass densities of the blade $(1,035 \mathrm{~kg} / \mathrm{m} 3)$ and tower $(10,350 \mathrm{~kg} / \mathrm{m} 3)$ were determined to find the total weight. The weights of one blade and the tower were 60.2 and $3317 \mathrm{~kg}$, respectively. In Table-2, the applied mass values are classified according to the NREL report [3]. As shown in Fig. 
15 and listed in Table-2, all the masses of the mechanical parts were defined as point masses, in

2 contrast to the blade and tower, which were defined by the effective mass. As shown in Fig. 5, there

3 were four point mass numbers for the mechanical parts. Two point masses were defined at the root

4 of the blade for the pitch shaft and the other parts (bull gear, instrumentation, bearing, nut, and

5 spacers) (38.6 kg each). To define the hub components, including the hub, boom, instrumentation

6 enclosures, and camera, one point mass $(380 \mathrm{~kg})$ was used at the hub's center point. The nacelle's

7 mass $(1256 \mathrm{~kg})$ was defined by one point mass at the intersection point of the tower center and rotor

8 center line. The total turbine mass was calculated to be $5149 \mathrm{~kg}$. Not counting the blade mass, the

9 total mass of the top of the tower could be determined to be $1712 \mathrm{~kg}$, which included the mass of the nacelle, hub, and shafts, and was $51.6 \%$ of the tower mass. The mass of the two blades was $120.4 \mathrm{~kg}$, which was only $3.6 \%$ of the tower mass. The total rotor mass was $577.3 \mathrm{~kg}$, including the two blades $(120.4 \mathrm{~kg})$. It can easily be predicted that the natural frequencies of the turbine and tower were not dependent on the blade but on the mass of the nacelle and hub. However, the structural response of the turbine was highly dependent on the blade, because the flexible blade had a large surface area $(10.8 \mathrm{~m} 2)$ compared with its mass, and the rotating blade was designed to optimize the aerodynamic efficiency.

With the exception of the tower and blade, the structural characteristics of the hub, shaft, connection details, and nacelle were shown to be mechanical characteristics. The unit length stiffness and unit mass were higher than those of the blade and tower, since the stiffness of the mechanical parts could be regarded as semi-rigid. However, the mechanical parts made serious and important mass contributions to the natural frequency. Thus, measured values had to be used for the mass values of the mechanical parts. Those of the blade and tower were the most important quantities for the structural stiffness. The tower was made of steel pipes. It had clear stiffness and mass distributions and supported the other parts. The overall structural characteristics might be dependent on the tower. 
1 As shown in Fig. 3, the stiffness and mass distributions of the blade were not easy to define.

2 Therefore, NREL estimated its sectional stiffness and mass properties [3]. Fig. 6, Fig. 7, and Fig. 8

3 explain the mass per unit length $(\mathrm{kg} / \mathrm{m})$, accumulative mass $(\mathrm{kg})$ and axial stiffness $(\mathrm{Nm})$ and along

4 the span-wise length respectively along with the value of present study. And Table-3 and Table-4

5 show the material properties of blade as describe in NREL [3] and present study (case1 and case2 in

6 Table-1). The blade had a span of $5.03 \mathrm{~m}$ and was connected to the stiff hub by the pitch shaft. The

7 original and FE model's pitch shaft are illustrated in Fig. 4.

8 Fig. 6 shows the mass per unit length of blade based on NREL's reported values, which were 9 obtained by measurement [3]. Fig. 7 shows the accumulated blade mass through the blade tip. The total blade mass was calculated to be $60.2 \mathrm{~kg}$ in our study, which exactly matched the NREL value listed in Table-2 [3]. However, NREL's accumulated mass was $94.0 \mathrm{~kg}$, which is $33.8 \mathrm{~kg}$ greater than the blade mass of $60.2 \mathrm{~kg}$. It can be assumed that some parts such as the blade root, pitch shaft, and bull gear might have been attached to root of the blade when it was measured. As listed in Table-2, the total mass of the pitch shaft, bull gear, instrumentation, bearings, nut, and spacers is $38.6 \mathrm{~kg}$, which is close to the $33.8 \mathrm{~kg}$ of excess mass for the blade. In this study, a point mass of $38.6 \mathrm{~kg}$ was inserted at the root end of the blade to simulate the total mass of the pitch shaft, bull gear, instrumentation, bearings, nut, and spacers. Except for the root region, the mass distribution of our blade model from 1.0 to $5.05 \mathrm{~m}$ was in good agreement with the NREL data. The natural frequency and eigen-mode of the flexible blade had a stronger relationship with the tip region than the root, which was stiffer or more semi-rigid than the rest. The distance to the root from the axis was shorter than the original, and the pitch shaft was connected to the root. The effect of the discrepancy on the natural frequency, as shown in Fig. 6 and Fig. 7, was negligible.

Fig. 8 shows the axial stiffness values for case 1 and case 2 of Table-1 with the NREL values [3]. The NREL's axial stiffness distribution near the hub, or root region, is much higher than that for the 
other region. This can be explained by Fig. 6 and Fig. 7. The stiffness distribution of case 2 was similar to that of NREL, whereas case 1 was lower. As discussed in the following chapter, these two cases were used for parametric studies to test the calculated natural frequencies of the blade. Young's elastic modulus for case 1 was $19 \%$ of that for case 2 , which implied that case 1 was five times as flexible as case 2 .

\section{Eigen-value analysis of blade}

The natural frequency is commonly used to verify structural properties. It depends on the mass and stiffness. The mass quantities are easier to define and measure than the stiffness. The masses of mechanical parts are applied using point masses, which are typically used in the rigid body dynamics. However, the blade had a complex geometry to define. As shown in Fig. 6 and Fig. 7, the mass distribution of the blade showed good agreement with the measurements, except for the root region. To test the validity of the blade's sectional properties, the eigen-value analysis were performed for various parameters.

The various mesh types and pitch angles were also tested to get the influences of mesh quality and blade pitch angle effects with material case1 in Table-1. Fig. 9 shows the geometry and Mesh type2 of one blade for the eigen-value analysis to obtain the natural frequencies and modes with entire turbine system was assembled. Table-5 and Fig. 10 describe the mesh conditions, mesh configurations and 1st mode shape with natural frequencies according to the mesh types when material case 1 was used. The geometry, mesh, and eigen-value analyses were performed using the commercial computer-aided engineering software ANSYS (version 13). Mesh type1 is coarse mesh with little number of elements. And Mesh type3 is finest mesh model with smallest maximum face size $(0.02 \mathrm{~m})$. From Mesh type1 to Mesh type3, the mapped face mesh was defined on the blade surface. The mesh condition of Mesh type4 is same with Mesh type2 except mapped face option in 
1 order to investigate the mapped mesh on blade. As illustrated in Fig. 10, the mesh quality effects

2 were not obtained in eigen-value analysis. This shows the natural mode shape is governed by the 3 global structural characteristics not localized mesh qualities. Even though, the quality of Mesh 4 type 1 is less than the others, it is enough to present the overall structural characteristics. The higher 5 number of elements( in Mesh type3 or Mesh type4) have little effects on the eigen-values results.

6 From the mesh quality parametric studies, the Mesh type 2 was selected in the studies of eigen-value $7 \quad$ analysis to verify the material properties. However the mesh quality tests will be further discussed 8 in importing the blade surface pressure information in FSI analysis.

Table-6 lists the natural frequencies and modes of this study based on an experiment, and Fig. 11 11 illustrates the mode shapes of case 1 up to the 3 rd mode when Mesh type 2 was used. The first and 12 third mode shapes are shown in the flap-wise direction, and the second mode shape is in the edge13 wise direction. The eigen-frequencies and mode shapes were in good agreement with the results of 14 the experiment. There were few discrepancies in the measured frequencies between the 15 instrumented and non-instrumented blades. Thus, the instrumentation can be understood to have a 16 negligible effect on the structural characteristics and natural frequency. The natural frequencies of case 1 and case 2 were calculated to be 7.266 and $16.611 \mathrm{~Hz}$, respectively. The eigen-value results for case 1 were closer to the experimental values than those of case 2, as shown in Fig. 8. As listed in Table-1, the stiffness of case 1 was less than that of case 2. Therefore, the natural frequency of case 2 could be higher than that of case 1 . The stiffness distributions of case 1 were lower than those of case 2, and the results of case 1 showed better agreement with the experiment than those of case 2.

24 The simplified eigen-value system for a blade can be written as follows, where the natural 25 frequency is proportional to the square root of the stiffness. 
$1 \quad f_{1}=\lambda \sqrt{k / m}$

2 where $f_{1}$ is the natural frequency, $\lambda$ is a proportional constant, $k$ is the stiffness, and $m$ is the

3 mass. Thus, the following simple equation should be valid.

$4 \quad f_{1}^{\text {casel }} / f_{1}^{\text {case } 2}=\sqrt{k 1 / k 2}$

5 where $f_{1}^{\text {casel }}, f_{1}^{\text {case } 2}, k 1$, and $k 2$ are the natural frequencies and stiffness values for case 1 and

6 case 2, respectively. Moreover, our natural frequencies and stiffness values for case 1 and case 2

7 show a good match with the results of equation (2).

$8 \quad\left(\left(f_{1}^{\text {casel }} / f_{1}^{\text {case } 2}\right)=0.437\right) \cong(\sqrt{k 1 / k 2}=0.436)$

9 As previously explained and shown in Fig. 6 and Fig. 7, the mass distributions of the blade can be said to be acceptable, except for the root region. This indicates that the sectional area and volume

11 distributions of the blade were also properly determined. It is interesting that the axial stiffness 12 distributions of case 2 were in good agreement with the measurements, as shown in Fig. 8. If the 13 material property of case 2 is selected for the effective stiffness of the blade, the structural stiffness 14 becomes stronger than the experimental result. In other words, the measured blade stiffness may 15 contain improper information. It is necessary to further investigate the discrepancy in the stiffness 16 distribution of case 1 through comprehensive research. Despite this discrepancy, the material property of case 1 was selected for the effective stiffness of the blade in this study to obtain a more accurate natural frequency. Fig. 12 shows the blade pitch angle effects on the natural frequencies. As easily predictable, the eigen-value and its corresponding modes are not dependent to its local coordinate systems and pitch angles on blade alone model. The pitch angle may not have negligible effects on whole turbine system but not significant rather little, because of blade's light mass (1.8\%) compared with whole system. 


\section{5. Eigen-value analysis of entire turbine blade}

2 An eigen-value analysis was performed to test the entire wind turbine's structural properties. Fig. 13

3 shows the geometry and mesh model of the entire turbine system. The commercial code Ansys- 13

4 was used for the study, with a total mesh number of 92,000. Fig. 14 shows a photo of the

5 experiment in NASA's Ames Research Center for a $90^{\circ}$ azimuth angle. A steel reaction mass was

6 suspended from a gantry crane to measure the frequencies. NREL has reported various natural

7 frequencies $(1.670,1.340$, and $1.740 \mathrm{~Hz})$ for various configurations, including the operation, turbine

8 without a blade, and tower-alone cases, respectively, as shown in Fig. 15.

In this study, various azimuth angles and material properties were considered to investigate the vibrating characteristics of the wind turbine. Fig. 15 illustrates these azimuth angles and wind turbine configurations. Except for the tower-alone case, multiple material properties were tested for the operational turbine with various azimuth angles and with the blades removed to investigate the effects of the azimuth angle on the natural frequency. Azimuth angles of $90^{\circ}, 45^{\circ}$, and $0^{\circ}$ were used, as shown in Fig. 15. However, NREL did not report the effects of the azimuth angles. Table-7 lists the results of the eigen-value analyses, with NREL's measurements.

The natural frequency for the $90^{\circ}$ azimuth angle with the material of case 1 was calculated to be $1.667 \mathrm{~Hz}$, which showed good agreement with NREL's value of $1.670 \mathrm{~Hz}$. Thus, the validity of the geometry and material property of case 1 could be verified. The natural frequencies for the $90^{\circ}, 45^{\circ}$, and $0^{\circ}$ azimuth angles were calculated to be $1.667,1.661$, and $1.665 \mathrm{~Hz}$ with the case 1 material property, respectively, which were all close to NREL's $90^{\circ}$ azimuth angle frequency of $1.670 \mathrm{~Hz}$.

The azimuth angle represents the rotating angle of the blade rotor about the primary axis. The total mass of the blades $(120.4 \mathrm{~kg})$ was only $2.34 \%$ of the total turbine mass $(5133 \mathrm{~kg})$. The stiffness and 
mass ratios of the blades to those of the whole turbine system were small. Thus, the effects of the azimuth angle could be negligible because of blade's light mass. The material property of case 2 produced rigid mechanical parts and higher blade stiffness than case 1. Case 3 has the blade material property of case 1 and rigid mechanical parts. As listed in Table-2, the natural frequencies for the $90^{\circ}$ azimuth angle with the material properties of case 2 and case 3 were calculated to be 2.778 and $2.774 \mathrm{~Hz}$, respectively, which were 1.111 and $1.107 \mathrm{~Hz}$ higher than that of case 1 . There was little discrepancy between case 2 and case 3 . The difference between case 2 and case 3 was the material property of the blade. Fig. 16 shows the first eigen-modes and natural frequencies according to the material cases for the $90^{\circ}$ azimuth angle. When a rigid material was assumed for the mechanical parts, including the nacelle, the top of the tower was un-deformed, and the blade's motion was dependent on the material property. However, the blade's material property did not affect the natural frequency. Similar behaviors can be seen for $45^{\circ}$ and $0^{\circ}$ azimuth angles, as shown in Fig. 17 and Fig. 18, respectively.

The stiffness of the mechanical parts did affect the structural property and vibrating behavior. If it is not clear, the material property of the mechanical parts can be assumed to be rigid within an acceptable range without significantly increasing the natural frequency. However the mass quantity should be accurately defined in any case to assure the validity of the analysis.

As shown in Fig. 15 and listed in Table-7, the natural frequencies of the blade-removed and toweralone configurations were calculated to be 1.719 and $3.865 \mathrm{~Hz}$, respectively, which were 0.052 (3\%) and $2.188 \mathrm{~Hz}(132 \%)$ higher than that of the operational turbine, respectively. Similar to the azimuth angle effects previously discussed, because of its light weight, removing the blade had little effects on the overall structural vibration characteristics in blade-removed case $(1.719 \mathrm{~Hz})$. However, the calculated natural frequency did not match with the NREL's value $(1.34 \mathrm{~Hz})(78 \%)$. The natural frequency of the tower-alone configuration, in which the nacelle and rotor were 
1 removed, was calculated as $3.865 \mathrm{~Hz}$. This value was much higher than that of the operational

2 turbine, which could be explained by the fact that the large mass $(1833 \mathrm{~kg})$ loaded on the top of the

3 tower was 15.3 times higher than that of the blade. The calculated value was also shown to have a

4 large discrepancy compared with the NREL's value $(1.75 \mathrm{~Hz})(45.3 \%)$. Even though higher mass of

5 nacelle and rotor removed, NREL's reported measured natural frequency of tower alone model is

6 similar to the operational model. And the NREL's measured natural frequencies are irregular pattern

$7 \quad(1.67 \mathrm{~Hz}, 1.34 \mathrm{~Hz}, 1.75 \mathrm{~Hz})$. The results of eigen-value analysis are shown to be reasonable values

8 according to the mass removal. And the result of eigen-value of operational wind turbine is good

9 match with measured data. Therefore, the proposed structural FE model of this study can be 10 acceptable.

11

Fig. 19 shows the eigen-modes of the operational model with the $90^{\circ}$ azimuth angle and case 1 material property. As shown in Fig. 19, the governing modes of the entire turbine system were the first and second modes. These two modes were similar and governed by the tower in the downstream and rotating directions. The next two modes were the blade's motions, which were similar to the blade's first and second modes, as shown in Fig. 11. The blade's first and second mode shapes were in the flapwise and edgewise directions. The fifth mode was the coupled motion of the blade and nacelle. The eigen-frequencies of the first and second modes were similar, where the third frequency was comparatively higher. These phenomena were also shown in the other turbine configuration cases. Thus, the first two modes that occurred on the turbine tower governed the entire turbine system in each of the turbine configurations: the operational, blade-removed, and tower-alone cases. In addition, the blade and nacelle had little effect on the vibrating modes of the entire turbine system, but had local and regional effects. The number of modes obtained from the eigen-value analysis was smaller than that of the experiment, because the geometries of the mechanical parts were simplified, and the point mass concept was used for this study. However the 
1 missed modes may have little effect on the governing behavior of entire turbine system, because the

2 entire turbine system may be governed by the natural frequency of first mode shape. The blade had

3 a low mass and flexible stiffness characteristic. When it rotated, the aerodynamic torque and thrust

4 forces were loaded on the blade surface, and the wind turbine began to vibrate. The rotating effects

5 of the loaded light and flexible blade on the entire turbine system could be important. However, it

6 can be said that the light blade had little effect on the natural frequency or vibrating characteristic of

7 the entire turbine system.

\section{Discussion of the application of verified structural FE model}

The purpose of the study is developing a structural model for structural analysis for NREL Phase VI wind turbine. In order to verify the validity of it, the simple and easy eigen-value analyses were used and compared the values with NREL's measured frequencies. The accuracy of structural analysis is highly dependent to the structural model. Therefore the verification of developed structural FE model is very important. In this study, the whole NREL Phase VI turbine was considered which is assembled by the blades, rotor, nacelle and tower. To get proper material properties, the parametric studies for material properties, mesh condition, and blade's configurations were considered. From the obtained natural frequencies of blade alone and whole turbine models, the validity of proposing structural FE model could be verified, even though discrepancies were found in the case of tower alone model. However the results of blade alone and operational turbine model were good agreement with NREL's measured data. If the structural model verified, it can be used in structural analysis.

In the case of wind turbine, the wind blade is loaded by aerodynamic force. To analysis the structural behavior of wind turbine, the accurate aerodynamic force should be evaluated before. And the evaluated aerodynamic force should be applied to the wind turbine in proper way. If the 
1 BEM process is considered, the sectional aerodynamic force of drag and lift forces could be 2 converted to global torque and thrust forces. And these global aerodynamic forces are loaded to the 3 blade as a nodal force. To get the valid aerodynamic information, the wind tunnel results usually used. And this BEM method is recognized as conventional design process. To improve the results, the 3D FE model can be used in references $[8,9,10,11]$. However from the difficulties of developing the whole turbine system, the rotor, nacelle and tower are usually omitted in those studies. As a result, the important tower behaviors are frequently not found in those studies. To get more accurate structural response, the whole turbine system should be considered. But it is not easy. There are many unknown and difficulties. To overcome these difficulties, in this study, the effective material properties were considered, and the resulting eigen-modes were well matched with NREL's data.

As mentioned before, the evaluation of aerodynamic force is governing the structural response of wind turbine system. The design of wind turbine can be dependent to the evaluated aerodynamic force. There are little discussions about the accuracy of wind tunnel test. The wind tunnel test regarded as most accurate one. However it has many limitations in design of wind turbine. The alternative advanced design method can be fluid-structure interaction (FSI) analysis by combing or coupling the fluid and structural domain. To assure the accuracy of FSI analysis, verification of both of domains should be performed. The developed structural FE model can be used in FSI analysis with valid surface pressure information in fluid domain. If the structural model is not verified, the complete results of FSI must be not accurate. In this circumstance, the structural model of this study can be regarded as valid one. It has accurate 3D curved shape of blade which can be exactly match with fluid domain in topology. And the blade and tower connected by approximated rotor and nacelle. The behaviors of nacelle were well demonstrated in Figs. 15 to 18.

Fig. 20 conceptually illustrates the fluid-structure interaction process for NREL Phase VI wind turbine utilizing the developed structural FE model of this study with the processes of 1-way and 2way fluid-structure interaction. Nevertheless of differences, the BEM can be also defined as 1-way 
1 FSI which is weak coupling and indirect nature. For the BEM analysis, it should cooperate with

2 fluid domain information to get the aerodynamic force on blade. Both of FSI and BEM in 1-way

3 FSI, the steady state RANS CFD analysis was in-cooperated, and the structural analysis results are

4 static. In contrast 1-way FSI analysis, 2-way FSI needs rigorous computational efforts to combine

5 both of domains in the unsteady time integration. So, 2-way FSI analysis is much more difficult to

6 get valid result with proper fluid and structural domains. The detail descriptions about the CFD, 1-

7 way and 2-way FSI analyses are beyond the scope of this study. The more information about the

8 CFD and 1-way FSI are presented in references [20,21] respectively using the structural FE model

9 of this study. The 2-way FSI analysis will be presented in the following research papers. In this

10 study, the important and fundamental characteristics of structural FE model for fluid-structure

11 interaction are introduced. Those are more related to the structural and mesh behaviors which were

12 explained in eigen-value analyses demonstrated.

13 Fig. 21 shows the 1-way FSI analysis according to the mesh types which were discussed in Fig. 10

14 for blade's eigen-value analysis. Even though low quality mesh of Mesh type1, its natural frequency

15 was good match with the other meshes and show little dependencies of mesh quality for eigen-value

16 analysis and structural performance. This is commonly known behaviors of structural FE model

17 properties. In FE analysis, the nodal forces are frequently used for loading. However the wind blade

18 has complex aerodynamic characteristics, and there is no easy way to impose the blade surface

19 pressure load except direct converting the pressure information from CFD analysis by the FSI

20 analysis. When importing the pressure information from CFD, the mesh quality has important

21 influence on the mapping process between fluid and structure domains. The finer grids are needed

22 in CFD analysis to meet the near wall behavior of fluid such as separation and transition. Therefore

23 there are mismatch between two different grid and mesh quality. Fig. 21 (a) illustrates the Mesh

24 types and corresponding imported surface pressure load on structural FE model. After static FSI

25 analysis, the torque values were obtained for each mesh types according to the wind velocity cases. 
1 The results were compared with NREL's measured torque values as shown in Fig. 21 (b). In

2 contrast to the eigen-value analysis which has similar results, the grid quality has significant effect

3 on the resulting torque values on structural FE model. And the imported pressure loading are well

4 agreement with original CFD values in Mesh type3 and Mesh type4 cases. From the mesh quality

5 parametric tests, the accuracy of mesh types could be verified which could not found in eigen-value

6 analysis only. The more details and further discussions about the static 1-way FSI and steady state

7 CFD analysis were omitted in this manuscript because of scope of the research.

8 Fig. 22 explains the transient 2-way FSI analysis results for two structural models. The blade alone

9 and whole turbine models were analyzed by directly in-cooperated with unsteady RANS CFD

10 analysis. Unlike 1-way FSI analysis, in 2-way analysis, the fluid and structural domains are directly

11 connected with each other, and transfer the necessary information for the analysis. By recording the

12 nodal displacement at each time step, the vibrating behaviors of each structural model could be

13 obtained. Fig. 22 (b) and Fig. 22 (c) illustrate the vibrating nodal displacement for blade alone and

14 whole turbine system respectively. The 2-way FSI analysis imports the deformed pressure

15 information, and performs the dynamic transient structural analysis. Thus the damped final motions

16 are converging to the static behaviors, and the vibrating motions must show the natural frequency of

17 structural model. As shown in Fig. 22 (b) and (c), the vibrating motions of both structural models

18 are good agreement with analysis and experiments. It is very interesting that the whole turbine

19 model's vibrating motions are composed with blade and tower as shown in Fig. 22 (c). The position

20 of (a) is located near the hub, and show tower vibrating motion. The position of (c) is located near

21 the blade tip, and shows the blade vibrating motion initially. After damped out the blade motion, the

22 vibrating model of position (c) is similar to that of position (a). The dynamic behaviors of whole

23 turbine are completely different to the blade alone model which is damped out quickly to the static

24 motion. When the tower is not considered in structural analysis, many important behaviors of it

25 could be hidden as shown in Fig. 22. There are many analysis processes 2-way FSI analysis and 
more difficult than 1-way FSI analysis as explained before. The detailed descriptions about the 2way FSI analysis are out of the scope of this paper. The more information and results will be discussed in the following another papers. The main purpose of this paper is to show the process of developing and verifying the structural model of NREL Phase VI wind turbine for further studies.

\section{Conclusion}

In this study, an FE model for the NREL Phase VI wind turbine was developed based on the NREL's reported data to evaluate and verify the accuracy of its structural properties for use in future BEM and FSI analyses. Steel was used for the tower, and various material properties were tested for the blade and mechanical parts. With the exception of the blade and tower, point masses were applied to the mechanical parts. Eigen-value analyses were performed to calculate the natural frequencies of various model cases, and these were compared with the NREL's measured data.

In parametric studies, natural frequencies and eigen-modes similar to those found in the NREL's experiments could be obtained for the blade and entire turbine using the material property of case 1 . The vibrating characteristic of the entire turbine system was mainly affected by the tower, and then by the mechanical parts. The first and second modes were governed by the tower. The blade had little effect on the natural frequency of the entire turbine based on various azimuth angle tests because of its light mass. The natural frequency of the entire turbine system was highly affected by the mass participation of the mechanical parts. The natural frequency of the tower alone was calculated to be $3.865 \mathrm{~Hz}$, which is higher than those in the blade-removed and operational configurations (1.719 and $1.667 \mathrm{~Hz}$, respectively) with the case 1 material property. This could be explained by the fact that the large mass $(1833 \mathrm{~kg})$ loaded on the top of the tower was 15.3 times greater than that of the blade. The proposed FE model's natural frequency $(1.667 \mathrm{~Hz})$ for the operational configuration with case 1 was close to the NREL's measurement (1.67 Hz). However, 
1 the other cases, with the blade removed $(1.34 \mathrm{~Hz})$ and tower alone $(1.75 \mathrm{~Hz})$, were shown to have

2 large discrepancies. The number of modes obtained from eigen-value analyses was less than that of

3 the experiment, because the geometries of the mechanical parts were simplified, and the point mass

4 concept was used.

5 In contrast to that for the blade, which showed good agreement with the eigen-frequencies and

6 modes, the development of an exact FE model for the entire wind turbine was not easy. There were

7 numerous unknowns and complexities, especially for the mechanical parts. However, the developed

8 FE model of the NREL Phase VI wind turbine showed good agreement with the measured natural

9 frequency. The validity and accuracy of the effective material of case 1 were also shown for the

10 blade and entire turbine system together. Even though there were discrepancies between the eigen-

11 frequencies and experimental results for the entire turbine blade, the overall vibrating and structural

12 behaviors of the proposed FEM were shown to be in good agreement within the acceptable range

13 for the natural frequency. The developed FE model contained a continuous accurate blade surface

14 based on the NREL wind tunnel test. Thus, it could be used for a BEM or FSI analysis after

15 converting the CFD or wind tunnel test data to aerodynamic forces. In the following next research

16 papers, the application of the developed FE model to the BEM or FSI will be further described in 17 details.

\section{Acknowledgement}

21 This research was supported by the National Science Foundation (NSF) through the Center for 22 Energy and Environmental Sustainability (CEES), a CREST Center (Award No. 1036593). And 23 also was supported by a National Research Foundation of Korea (NRF) grant funded by the Korea 24 Government (MEST) (No. 2012R1A2A2A01043088). 


\section{References}

1. R.R. Ramsay, M.J. Hoffman, G.M. Gregorek, "Effects of Grit Roughness and Pitch Oscillation on the S809 Airfoil", NREL/TP-442-7817, National Renewable Energy Laboratory (NREL), 1995.

2. D.M. Sommers, "Design and Experimental Results for the S809 Airfoil", NREL/SR-4406918, National Renewable Energy Laboratory (NREL), 1997.

3. M. Hand, D. Simms, L.J. Fingersch, D. Jager, S. Larwood, J. Cotrell, S. Schreck, "Unsteady Aerodynamics Experiment Phase VI: Wind Tunnel Test Configurations and Available Data Campaigns", NREL/TP-500-29955, National Renewable Energy Laboratory (NREL), 2001.

4. D. Simms, S. Schreck, M. Hand, L.J. Fingersch, "NREL Unsteady Aerodynamics Experiment in the NASA-Ames Wind Tunnel: A Comparison of Predictions to Measurements", NREL/TP-500-29494, National Renewable Energy Laboratory (NREL), 2001.

5. H.S. Toft, J. D. Sørensen, "Reliability-based design of wind turbine blades", Structural Safety, Vol.33, pp.333-342, 2011.

6. G. Ingram, "Wind Turbine Blade Analysis using the Blade Element Momentum Method", Version 1.1, October 18, 2011.

7. R. Lanzafame, M. Messina, "Bem theory : How to take into account the radial flow inside of a 1-D numerical code", Renewable Energy, Vol.39, pp.440-446, 2012.

8. D. Cardenas, H. Elizalde, P. Marzocca, S. Gallegos, O. Probst, "A coupled aeroelastic damage progression model for wind turbine blades", Composite Structures, Vol.94, pp.3072-3081, 2012.

9. L.I. Lago, F.L. Ponta, A.D. Otero, "Analysis of alternative adaptive geometrical configurations for the NREL-5 MW wind turbine blade", Renewable Energy, Vol.59, pp.13$22,2013$. 
10. A. Sharifi, M.R.H. Nobari, "Prediction of optimum section pitch angle distribution along wind turbine blades", Energy Conversion and Management, Vol.67, pp.342-350, 2013.

11. Y. Bazilevs, M.-C. Hsu, J. Kiendl, R. Wüchner,K.-U. Bletzinger, “3D simulation of wind turbine rotors at full scale. Part II: Fluid-structure interaction modeling with composite blades”, International Journal for Numerical Methods in Fluids, Vol.65, pp.236-253, 2011.

12. Y. Bazilevs, M.C. Hsua, M.A. Scottb, "Isogeometric fluidstructure interaction analysis with emphasis on non-matching discretizations, and with application to wind turbines", Computer Methods in Applied Mechanics and Engineering, Vol.249-252, pp.28-41, 2012.

13. E.P.N. Duque, M.D. Burkund, W. Johnson, "Navier-Stokes and comprehensive analysis performance predictions of the NREL phase VI experiment", Journal of Solar Energy Engineering, Vol.125, pp.457-467, 2003.

14. J.O. Mo, Y.H. Lee, "CFD Investigation on the aerodynamic characteristics of a small-sized wind turbine of NREL PHASE VI operating with a stall-regulated method", Journal of Mechanical Science and Technology, Vol.26(1), pp.81-92, 2012.

15. M. Moshfeghi, Y.J. Song, Y.H. Xie, "Effects of near-wall grid spacing on SST-K- $\omega$ model using NREL Phase VI horizontal axis wind turbine", Journal of Wind Engineering and Industrial Aerodynamics, Vol.107-108, pp.94-105, 2012

16. Y. Li, K.J. Paik, T. Xing, P.M. Carrica, "Dynamic overset CFD simulations of wind turbine aerodynamics", Renewable Energy, Vol.37(1), pp.285-298, 2012

17. M.M. Yelmule, VSJ E. Anjuri, "CFD predictions of NREL Phase VI Rotor Experiments in NASA/AMES Wind tunnel", Initernational Journal of Renewable Energy Research, Vol.3, pp.250-260, 2013

18. J.O. Mo, A. Choudhry, M. Arjomandi, "Richard Kelso, Young-Ho Lee, Effects of wind speed changes on wake instability of a wind turbine in a virtual wind tunnel using large eddy simulation", Journal of Wind Engineering and Industrial Aerodynamics, Vol.117, pp.38-56, 
2013.

2 19. R. Lanzafame, S. Mauro, M. Messina, "Wind turbine CFD modeling using a correlationbased transitional model", Renewabl Energy, Vol.52, pp.31-39. 2013.

20. K.S. Lee, Z. Huque, R. Kommalapati, S.E. Han, "Fluid-Structure Interaction Analysis of NREL Phase VI Wind Turbine Part-1: CFD analysis and Verification", Renewable Energy, 2015, Submitted.

21. K.S. Lee, Z. Huque, R. Kommalapati, S.E. Han, "Fluid-Structure Interaction Analysis of NREL Phase VI Wind Turbine Part-2: Aerodynamic Force Evaluation and Structural Analysis using FSI analysis", Renewable Energy, 2015, Submitted. 
$<$ Table. 1 $>$ Assumed material properties : Present study

\begin{tabular}{|c|c|c|c|c|c|}
\hline \multirow{2}{*}{ Components } & \multicolumn{3}{|c|}{ Material $(\mathrm{Pa})$} & \multirow{2}{*}{$\begin{array}{l}\text { Density } \\
(\mathrm{kg} / \mathrm{m} 3)\end{array}$} & \multirow{2}{*}{ Description } \\
\hline & Case 1 & Case 2 & Case 3 & & \\
\hline Blade & $\begin{array}{c}E=1.560 E+10 \\
v=0.42\end{array}$ & $\begin{array}{c}E=8.20 E+10 \\
v=0.42\end{array}$ & $\begin{array}{c}\text { Case1 } \\
(\mathrm{E}=1.560 \mathrm{E}+10 \\
\mathrm{v}=\mathbf{0 . 4 2})\end{array}$ & 1,035 & $\begin{array}{l}\text { Effective stiffness } \\
\text { and density }\end{array}$ \\
\hline $\begin{array}{l}\text { Nacelle, Hub, } \\
\text { Shaft, etc }\end{array}$ & Steel & Rigid & $\begin{array}{l}\text { Case2 } \\
\text { (Rigid) }\end{array}$ & - & Point mass \\
\hline Rigid link & \multicolumn{3}{|c|}{ Rigid } & - & Point mass \\
\hline Tower & \multicolumn{3}{|c|}{$\begin{array}{c}\text { Steel } \\
\text { (ASTM A106) }\end{array}$} & 10,350 & $\begin{array}{c}\text { Effective } \\
\text { density }\end{array}$ \\
\hline
\end{tabular}

$<$ Table. 2> Mass definitions for parts : NREL [3]

\begin{tabular}{|c|c|c|}
\hline Components & $\begin{array}{r}\text { Mass } \\
(\mathrm{kg})\end{array}$ & Description \\
\hline $\begin{array}{l}\text { Pitch shaft, } \\
\text { bull gear, } \\
\text { instrumentation, } \\
\text { bearings, } \\
\text { nut and spacers }\end{array}$ & 38.6 & Point mass \\
\hline Hub & 237.8 & Point mass \\
\hline $\begin{array}{c}\text { Boom, } \\
\text { instrumentation } \\
\text { enclosures and } \\
\text { camera }\end{array}$ & 141.9 & Point mass \\
\hline Nacelle & 1256.0 & Point mass \\
\hline $\begin{array}{l}\text { Blade1 mass } \\
\text { (standard tip) }\end{array}$ & 60.2 & Effective mass \\
\hline $\begin{array}{l}\text { Blade3 mass } \\
\text { (standard tip) }\end{array}$ & 60.2 & Effective mass \\
\hline Total rotor mass & 577.3 & - \\
\hline $\begin{array}{c}\text { Nacelle, } \\
\text { hub, } \\
\text { pitch shafts, } \\
\text { and boom mass }\end{array}$ & 1712.0 & Point mass \\
\hline $\begin{array}{c}\text { Tower mass } \\
\text { Pipe-609.6x17.5 (base) } \\
\text { Pipe-406.4x21.4 (top) }\end{array}$ & $\begin{array}{c}3300.0 \\
(3317.0)\end{array}$ & $\begin{array}{l}\text { Effective mass } \\
\text { (mass of NREL) }\end{array}$ \\
\hline
\end{tabular}


$<$ Table. 3> Estimated blade structural properties: NREL [3]

\begin{tabular}{|c|c|c|c|c|c|}
\hline No. & $\begin{array}{l}\text { Distance from } \\
\text { Center of } \\
\text { Rotation (m) }\end{array}$ & $\begin{array}{l}\text { Sectional Mass } \\
\text { Per Unit Length } \\
(\mathrm{kg} / \mathrm{m})\end{array}$ & $\begin{array}{c}\operatorname{mass} \\
(\mathrm{kg})\end{array}$ & $\begin{array}{l}\text { Accumulative } \\
\text { Mass (kg) }\end{array}$ & $\begin{array}{l}\text { Axial Stiffness } \\
(\mathrm{Nm})\end{array}$ \\
\hline 1 & 0.369 & 34.784 & 12.84 & 12.84 & $1.04 \mathrm{E}+09$ \\
\hline 2 & 0.483 & 223.970 & 25.53 & 38.37 & $6.69 \mathrm{E}+09$ \\
\hline 3 & 0.508 & 39.557 & 0.99 & 39.36 & $1.01 \mathrm{E}+09$ \\
\hline 4 & 0.559 & 50.797 & 2.59 & 41.95 & $1.48 \mathrm{E}+09$ \\
\hline 5 & 0.610 & 44.797 & 2.28 & 44.23 & $1.33 \mathrm{E}+09$ \\
\hline 6 & 0.660 & 33.797 & 1.69 & 45.92 & $1.03 \mathrm{E}+09$ \\
\hline 7 & 0.883 & 9.973 & 2.22 & 48.15 & $3.95 \mathrm{E}+08$ \\
\hline 8 & 1.257 & 16.265 & 6.08 & 54.23 & $4.07 \mathrm{E}+08$ \\
\hline 9 & 1.343 & 16.134 & 1.39 & 55.62 & $4.04 \mathrm{E}+08$ \\
\hline 10 & 1.510 & 15.623 & 2.61 & 58.23 & $3.84 \mathrm{E}+08$ \\
\hline 11 & 1.648 & 15.210 & 2.10 & 60.32 & $3.67 \mathrm{E}+08$ \\
\hline 12 & 1.952 & 14.741 & 4.48 & 64.81 & $3.57 \mathrm{E}+08$ \\
\hline 13 & 2.257 & 14.379 & 4.39 & 69.19 & $3.52 \mathrm{E}+08$ \\
\hline 14 & 2.343 & 12.380 & 1.06 & 70.26 & $3.21 \mathrm{E}+08$ \\
\hline 15 & 2.562 & 11.705 & 2.56 & 72.82 & $2.92 \mathrm{E}+08$ \\
\hline 16 & 2.867 & 10.853 & 3.31 & 76.13 & $2.56 \mathrm{E}+08$ \\
\hline 17 & 3.172 & 10.279 & 3.14 & 79.26 & $2.36 \mathrm{E}+08$ \\
\hline 18 & 3.185 & 10.253 & 0.13 & 79.40 & $2.35 \mathrm{E}+08$ \\
\hline 19 & 3.476 & 9.585 & 2.79 & 82.19 & $2.10 \mathrm{E}+08$ \\
\hline 20 & 3.781 & 8.935 & 2.73 & 84.91 & $1.85 \mathrm{E}+08$ \\
\hline 21 & 4.023 & 8.416 & 2.04 & 86.95 & $1.66 \mathrm{E}+08$ \\
\hline 22 & 4.086 & 8.291 & 0.52 & 87.47 & $1.61 \mathrm{E}+08$ \\
\hline 23 & 4.391 & 7.672 & 2.34 & 89.81 & $1.38 \mathrm{E}+08$ \\
\hline 24 & 4.696 & 7.043 & 2.15 & 91.96 & $1.15 \mathrm{E}+08$ \\
\hline 25 & 4.780 & 6.882 & 0.58 & 92.54 & $1.09 \mathrm{E}+08$ \\
\hline 26 & 5.000 & 6.440 & 1.42 & 93.95 & $9.36 \mathrm{E}+07$ \\
\hline
\end{tabular}


$<$ Table. 4> Assumed blade structural properties: Present study (Case1, Case2)

\begin{tabular}{c|r|r|r|r|r|r}
\hline No. & $\begin{array}{c}\text { Distance from } \\
\text { Center of } \\
\text { Rotation }(\mathrm{m})\end{array}$ & $\begin{array}{c}\text { Sectional Mass } \\
\text { Per Unit Length } \\
(\mathrm{kg} / \mathrm{m})\end{array}$ & $\begin{array}{c}\text { mass } \\
(\mathrm{kg})\end{array}$ & $\begin{array}{c}\text { Accumulative } \\
\text { Mass }(\mathrm{kg})\end{array}$ & $\begin{array}{c}\text { Axial } \\
\text { Stiffness : } \\
\text { Case1 (Nm) }\end{array}$ & $\begin{array}{c}\text { Axial } \\
\text { Stiffness : } \\
\text { Case2(Nm) }\end{array}$ \\
\hline 1 & 0.660 & 5.985 & 3.950 & 3.950 & $5.52 \mathrm{E}+07$ & $2.94 \mathrm{E}+08$ \\
\hline 2 & 0.883 & 18.861 & 4.206 & 8.156 & $6.26 \mathrm{E}+07$ & $3.33 \mathrm{E}+08$ \\
\hline 3 & 0.983 & 13.716 & 1.372 & 9.528 & $2.04 \mathrm{E}+07$ & $1.09 \mathrm{E}+08$ \\
\hline 4 & 1.083 & 16.875 & 1.688 & 11.215 & $2.51 \mathrm{E}+07$ & $1.34 \mathrm{E}+08$ \\
\hline 5 & 1.183 & 19.228 & 1.923 & 13.138 & $2.86 \mathrm{E}+07$ & $1.52 \mathrm{E}+08$ \\
\hline 6 & 1.257 & 20.646 & 1.528 & 14.666 & $2.27 \mathrm{E}+07$ & $1.21 \mathrm{E}+08$ \\
\hline 7 & 1.508 & 20.362 & 5.120 & 19.786 & $7.62 \mathrm{E}+07$ & $4.06 \mathrm{E}+08$ \\
\hline 8 & 1.760 & 18.916 & 4.756 & 24.542 & $7.08 \mathrm{E}+07$ & $3.77 \mathrm{E}+08$ \\
\hline 9 & 2.011 & 17.572 & 4.418 & 28.960 & $6.57 \mathrm{E}+07$ & $3.50 \mathrm{E}+08$ \\
\hline 10 & 2.263 & 16.269 & 4.091 & 33.051 & $6.09 \mathrm{E}+07$ & $3.24 \mathrm{E}+08$ \\
\hline 11 & 2.514 & 15.018 & 3.776 & 36.827 & $5.62 \mathrm{E}+07$ & $2.99 \mathrm{E}+08$ \\
\hline 12 & 2.766 & 13.817 & 3.474 & 40.302 & $5.17 \mathrm{E}+07$ & $2.75 \mathrm{E}+08$ \\
\hline 13 & 3.017 & 12.667 & 3.185 & 43.487 & $4.74 \mathrm{E}+07$ & $2.52 \mathrm{E}+08$ \\
\hline 14 & 3.269 & 11.568 & 2.909 & 46.396 & $4.33 \mathrm{E}+07$ & $2.30 \mathrm{E}+08$ \\
\hline 15 & 3.520 & 10.517 & 2.645 & 49.040 & $3.93 \mathrm{E}+07$ & $2.10 \mathrm{E}+08$ \\
\hline 16 & 3.772 & 9.517 & 2.393 & 51.433 & $3.56 \mathrm{E}+07$ & $1.90 \mathrm{E}+08$ \\
\hline 17 & 4.023 & 8.566 & 2.154 & 53.587 & $3.20 \mathrm{E}+07$ & $1.71 \mathrm{E}+08$ \\
\hline 18 & 4.274 & 7.665 & 1.927 & 55.514 & $2.87 \mathrm{E}+07$ & $1.53 \mathrm{E}+08$ \\
\hline 19 & 4.526 & 6.814 & 1.713 & 57.228 & $2.55 \mathrm{E}+07$ & $1.36 \mathrm{E}+08$ \\
\hline 20 & 4.777 & 5.959 & 1.498 & 58.726 & $2.23 \mathrm{E}+07$ & $1.19 \mathrm{E}+08$ \\
\hline 21 & 4.943 & 5.584 & 0.925 & 59.651 & $1.38 \mathrm{E}+07$ & $7.33 \mathrm{E}+07$ \\
\hline 22 & 5.030 & 5.591 & 0.486 & 60.138 & $7.24 \mathrm{E}+06$ & $3.85 \mathrm{E}+07$ \\
\hline
\end{tabular}


$<$ Table. $5>$ Mesh conditions according to the mesh types (m)

\begin{tabular}{|c|c|c|c|c|}
\hline & Mesh type1 & Mesh type2 & Mesh type3 & Mesh type4 \\
\hline $\begin{array}{l}\text { Mapped face } \\
\text { mesh on blade }\end{array}$ & on & on & on & off \\
\hline Relevance center & Coarse & Medium & Medium & Medium \\
\hline Smoothing & High & High & High & High \\
\hline Tansition & Fast & Fast & Fast & Fast \\
\hline Span angle center & Coarse & Medium & Fine & Medium \\
\hline Min size & 0.010 & 0.005 & 0.005 & 0.005 \\
\hline Max face size & 0.200 & 0.040 & 0.020 & 0.040 \\
\hline Max size & 0.300 & 0.200 & 0.200 & 0.200 \\
\hline Growth rate & 1.200 & 1.200 & 1.200 & 1.200 \\
\hline Min edge length & 0.003564 & 0.003564 & 0.003564 & 0.003564 \\
\hline Number of node & 15,024 & 46,284 & 192,240 & 207,284 \\
\hline Number of element & 8,276 & 25,880 & 112,998 & 120,951 \\
\hline \multicolumn{5}{|l|}{ Mesh shape } \\
\hline & Mesh type1 & Mesh type2 & Mesh type3 & Mesh type4 \\
\hline
\end{tabular}


$<$ Table. 6> Results of eigen-value analysis (Mesh type2): frequencies of blade comparison with NREL [3]

\begin{tabular}{c|c|c|c|c|c}
\hline \multirow{2}{*}{ Mode NO. } & \multicolumn{2}{|c|}{ Experiment (Hz) } & \multicolumn{2}{c}{ Present study (Hz) } & \multirow{2}{*}{ Description } \\
\cline { 2 - 5 } & Non-instrumented & Instrumented & Case 1 & Case 2 & \\
\hline 1 & 7.313 & 7.25 & 7.276 & 16.611 & \multirow{2}{*}{ First flapwise eigen-frequency } \\
\hline 2 & 9.062 & 8.9 & 12.668 & 28.288 & First edgewise eigen-frequency \\
\hline 3 & 30.062 & 29.438 & 28.561 & 65.167 & Second flapwise eigen-frequency \\
\hline
\end{tabular}

$<$ Table. $7>$ Results of eigen-value analysis (Mesh type2): frequencies of turbine according to the configurations and comparison with NREL [3]

\begin{tabular}{|c|c|c|c|c|c|c|c|c|c|c|c|c|c|c|c|}
\hline \multirow{4}{*}{$\begin{array}{l}\text { Mode } \\
\text { NO. }\end{array}$} & \multicolumn{10}{|c|}{ Operational Turbine (Hz) } & \multicolumn{3}{|c|}{$\begin{array}{c}\text { Turbine } \\
\text { with Blades Removed }(\mathrm{Hz})\end{array}$} & \multicolumn{2}{|c|}{ Tower Alone (Hz) } \\
\hline & \multirow{3}{*}{\begin{tabular}{|c}
$\begin{array}{c}\text { Experiment } \\
\text { (NREL) }\end{array}$ \\
$90^{\circ}$ \\
azimuth
\end{tabular}} & \multicolumn{9}{|c|}{ Present study } & \multirow{3}{*}{$\mid \begin{array}{c}\text { Experiment } \\
\text { (NREL) }\end{array}$} & \multirow{2}{*}{\multicolumn{2}{|c|}{ Present study }} & \multirow{3}{*}{$\begin{array}{c}\text { Experiment } \\
\text { (NREL) }\end{array}$} & \multirow{3}{*}{$\begin{array}{c}\text { Present } \\
\text { study }\end{array}$} \\
\hline & & \multicolumn{3}{|c|}{$90^{\circ}$ azimuth } & \multicolumn{3}{|c|}{$45^{\circ}$ azimuth } & \multicolumn{3}{|c|}{$0^{\circ}$ azimuth } & & & & & \\
\hline & & Case 1 & Case 2 & Case 3 & Case 1C & Case 2 & Case 3 & Case 1 & 1 Case 2 & Case 3 & & Case 1 & Case 2 & & \\
\hline 1 & 1.670 & 1.667 & 2.778 & 2.774 & 1.661 & 2.771 & 2.767 & 1.665 & 2.783 & 2.779 & 1.340 & 1.719 & 2.852 & 1.740 & 3.865 \\
\hline 2 & 1.750 & 1.668 & 2.800 & 2.780 & 1.666 & 2.797 & 2.796 & 1.666 & \begin{tabular}{|l|l|}
5.797 \\
\end{tabular} & 2.795 & 1.790 & 1.723 & 2.871 & 2.360 & 3.865 \\
\hline 3 & 2.470 & 6.029 & 16.313 & 7.228 & 6.5741 & 16.597 & 7.270 & 6.308 & 16.550 & 7.259 & 1.850 & 13.585 & 19.583 & 2.730 & 20.314 \\
\hline 4 & 5.860 & 6.787 & 16.715 & 7.3364 & 6.7991 & 16.753 & 7.357 & 6.803 & 16.740 & 7.346 & 5.920 & 13.981 & 19.748 & 3.910 & 20.315 \\
\hline 5 & 5.900 & 7.989 & 19.574 & 12.566 & \begin{tabular}{|l|l|}
7.993 & 1 \\
\end{tabular} & 19.507 & 12.653 & 38.009 & 19.632 & 212.640 & 7.100 & 17.301 & 48.474 & 4.030 & 51.891 \\
\hline 6 & 7.170 & 10.963 & 19.688 & 12.619 & 11.0001 & 19.675 & 12.706 & 10.838 & 819.676 & 612.797 & 8.550 & 30.101 & 49.115 & 8.140 & 51.895 \\
\hline 7 & 7.300 & 13.721 & 28.424 & 19.494 & 13.5242 & 28.712 & 19.462 & 13.494 & 428.858 & 19.583 & 11.010 & 39.151 & 64.197 & 10.380 & 81.513 \\
\hline 8 & 8.740 & 14.323 & 28.807 & 719.678 & 14.6872 & 28.929 & 19.698 & 14.628 & 829.371 & 19.735 & 11.620 & 50.899 & 89.337 & 10.660 & 100.430 \\
\hline 9 & 11.840 & 16.867 & 48.091 & 28.296 & 17.7114 & 47.970 & 28.494 & 17.469 & 948.631 & 28.468 & 12.680 & 67.141 & 95.125 & 11.930 & 100.430 \\
\hline 10 & 11.880 & 27.768 & 49.026 & 28.68 & 24.2204 & 49.040 & 28.737 & 26.311 & 149.074 & 428.699 & 14.560 & 71.718 & 104.87 & 14.010 & 112.950 \\
\hline
\end{tabular}




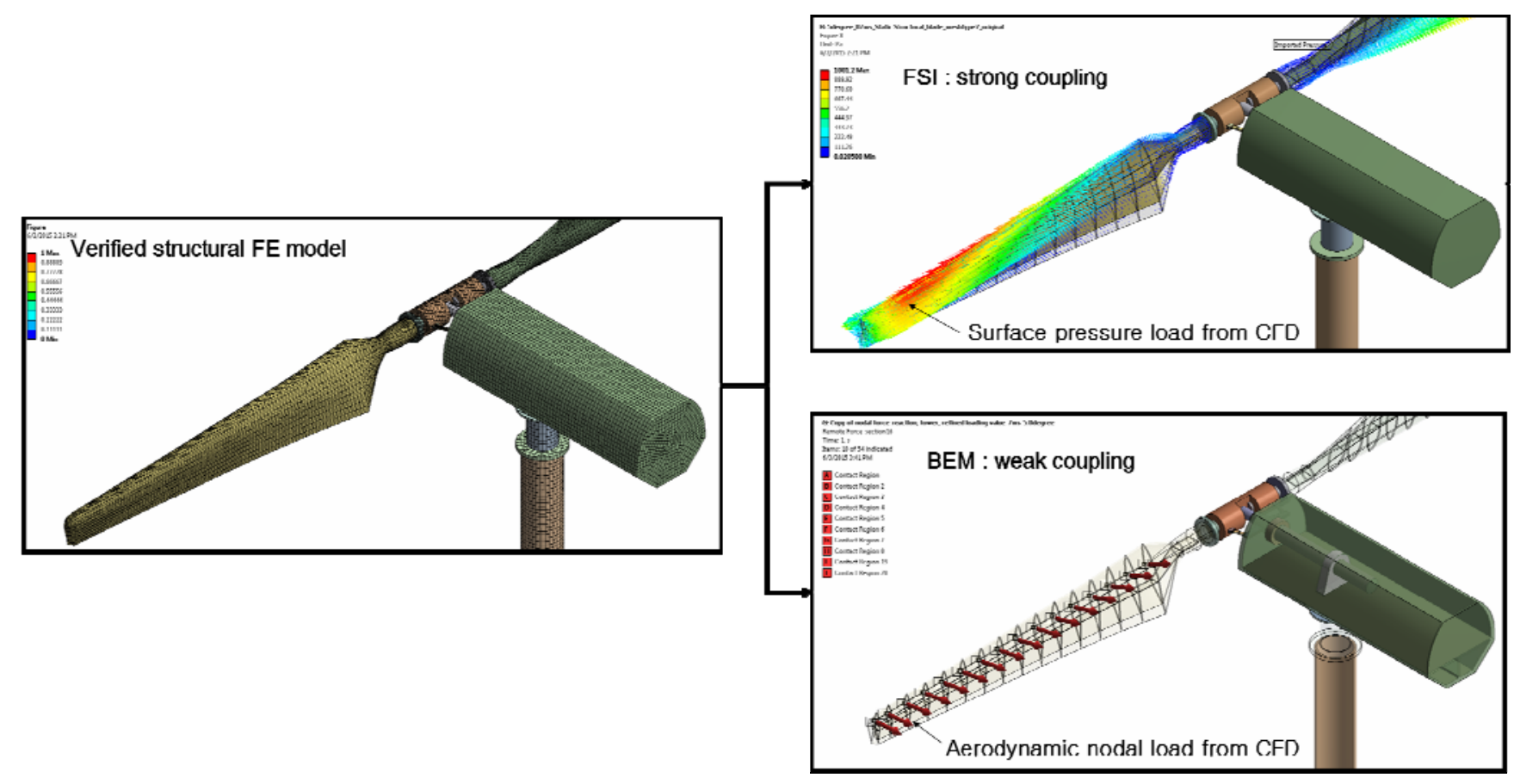

$<$ Fig. 1 $>$ Structural analysis of NREL Phase VI wind turbine using 1-way FSI or BEM processes 

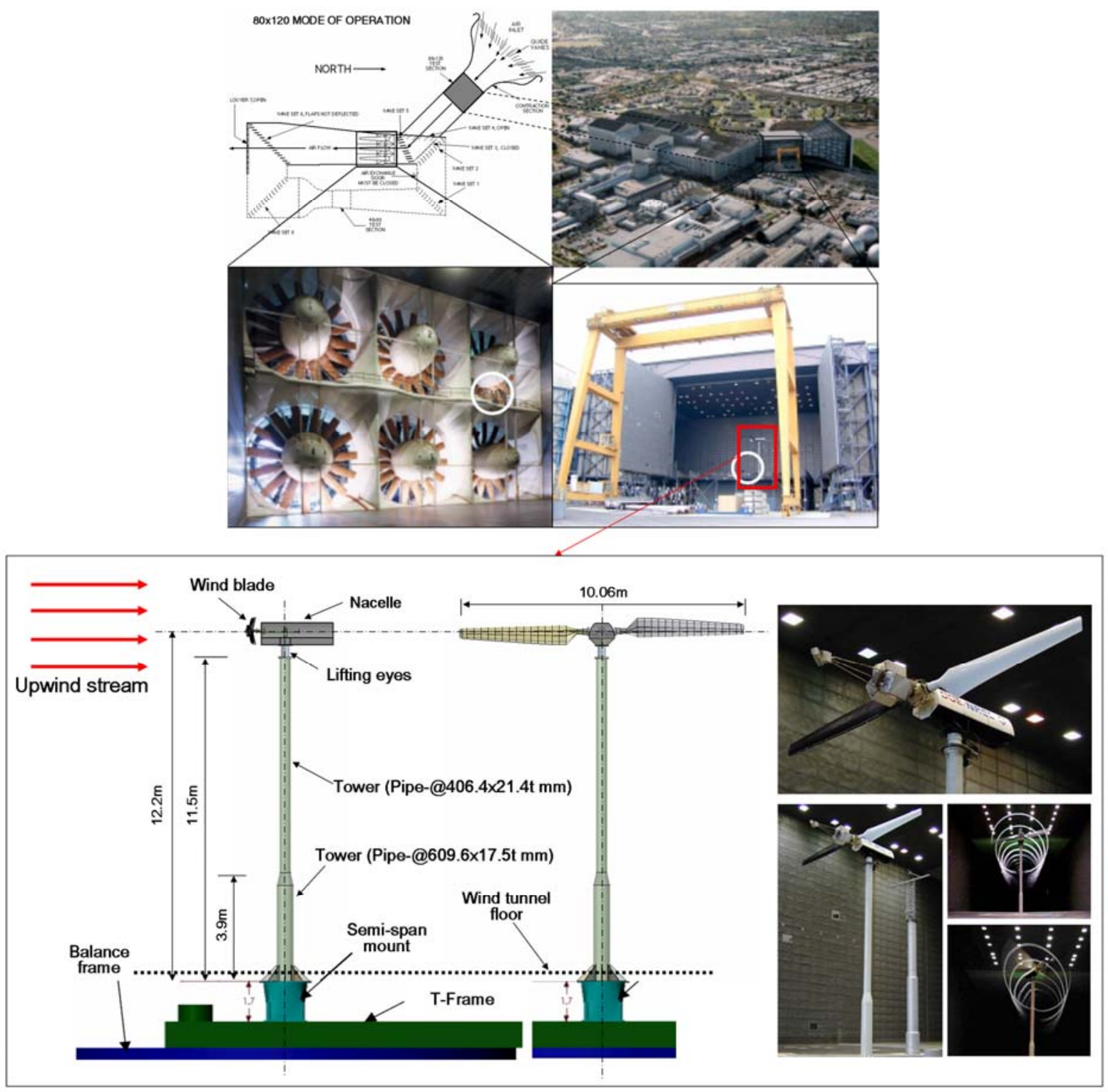

$<$ Fig. 2> NASA's Ames Research Center / NREL Phase VI wind turbine [3] 


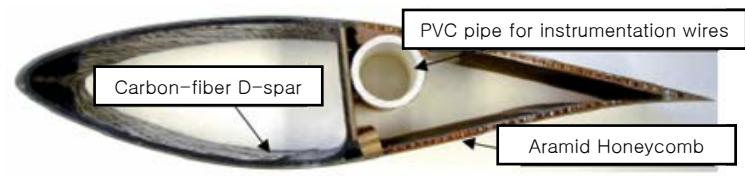

Full pressure Tap distribution

* * Pressure Taps at $4 \%$ and $36 \%$ Chord, Suction surface only
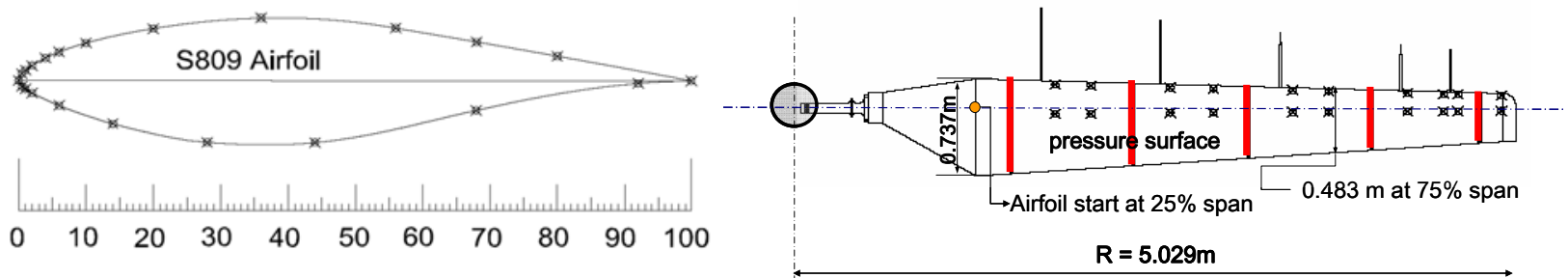

(a) Pressure tab locations on S809 airfoil

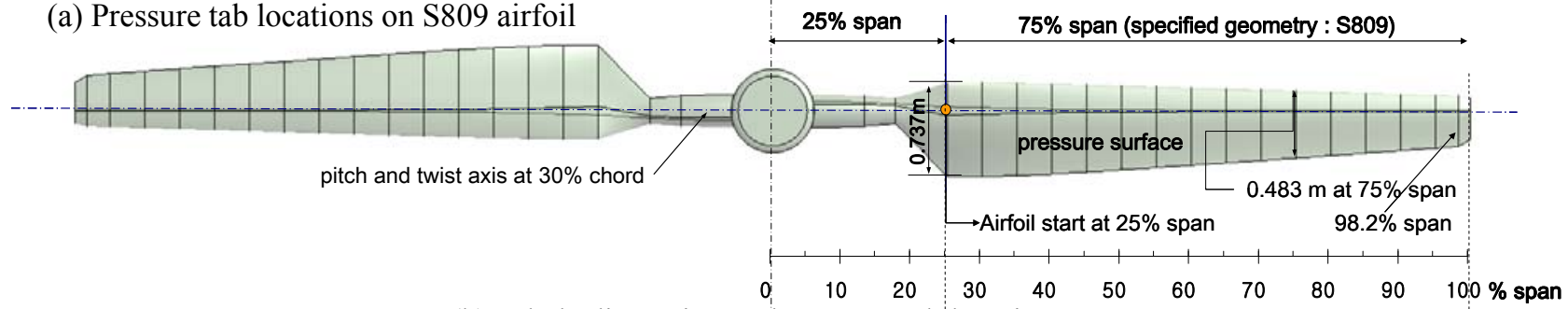

(b) Blade dimension and pressure tab location on span

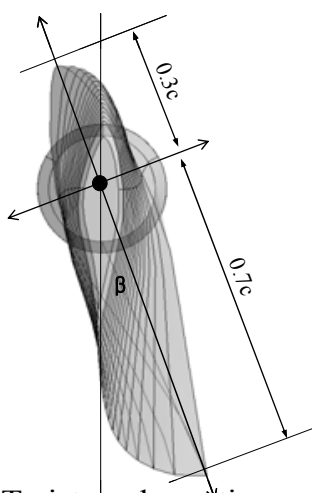

(c) Twist angle section

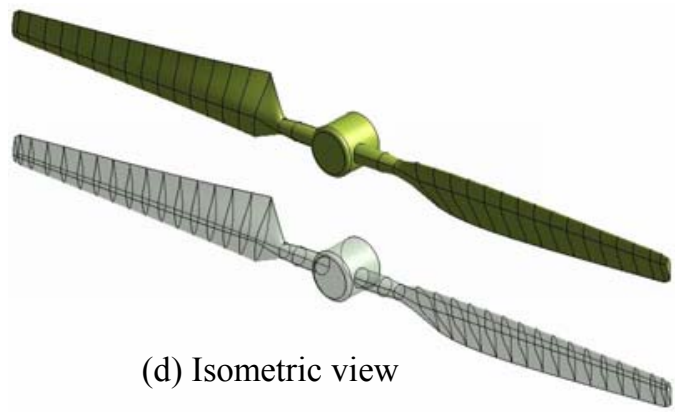

$<$ Fig. 3 $>$ Geometry of blade: section shape and pressure tab locations [3]
- Present study: Tw is t angle(deg.)

-NREL Phase VI: Tw is t angle(deg.)

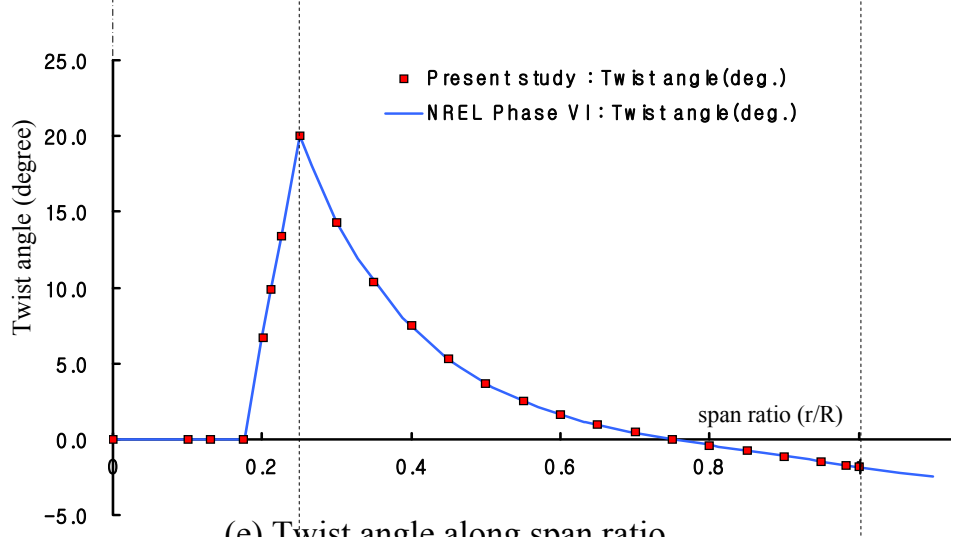

(e) Twist angle along span ratio

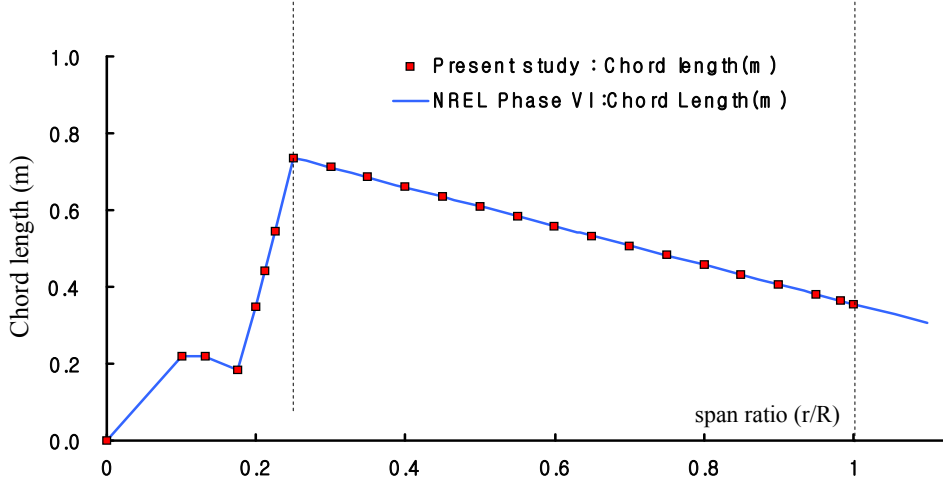

(f) Taper (chord length) along span ratio 


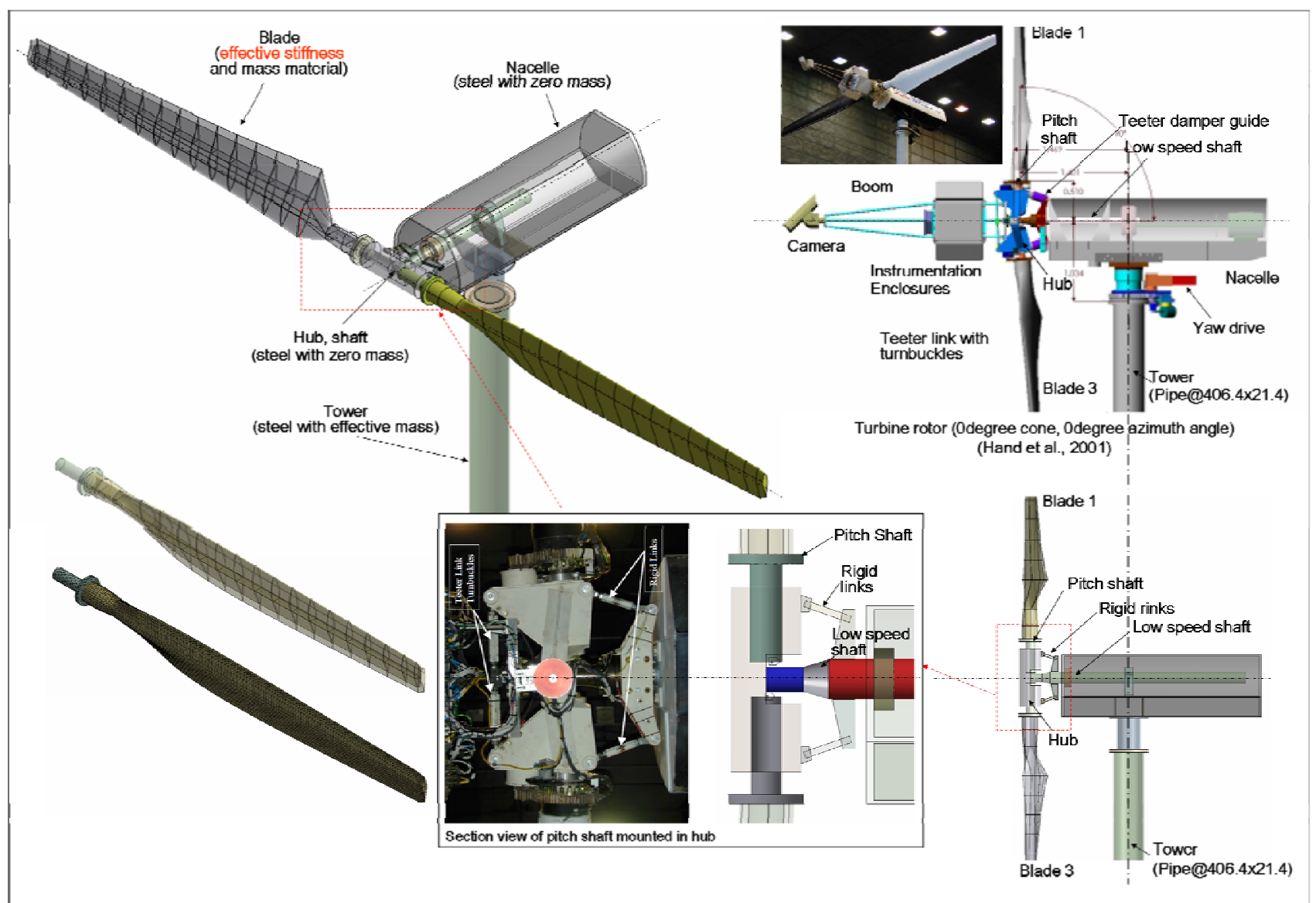

$<$ Fig. 4> Geometry of hub, shaft and nacelle geometry [3] 


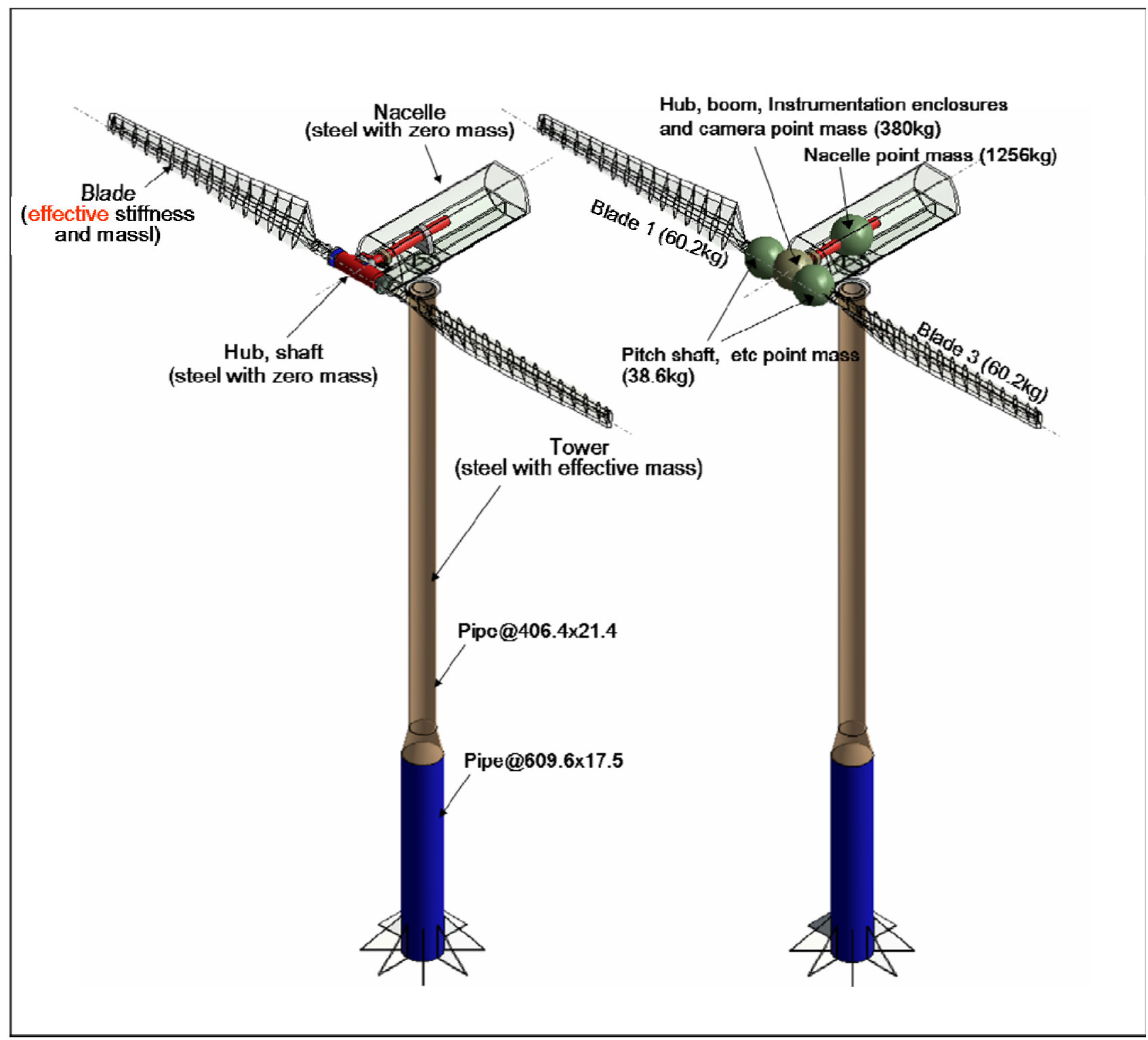

$<$ Fig. 5 $>$ Mass definitions 


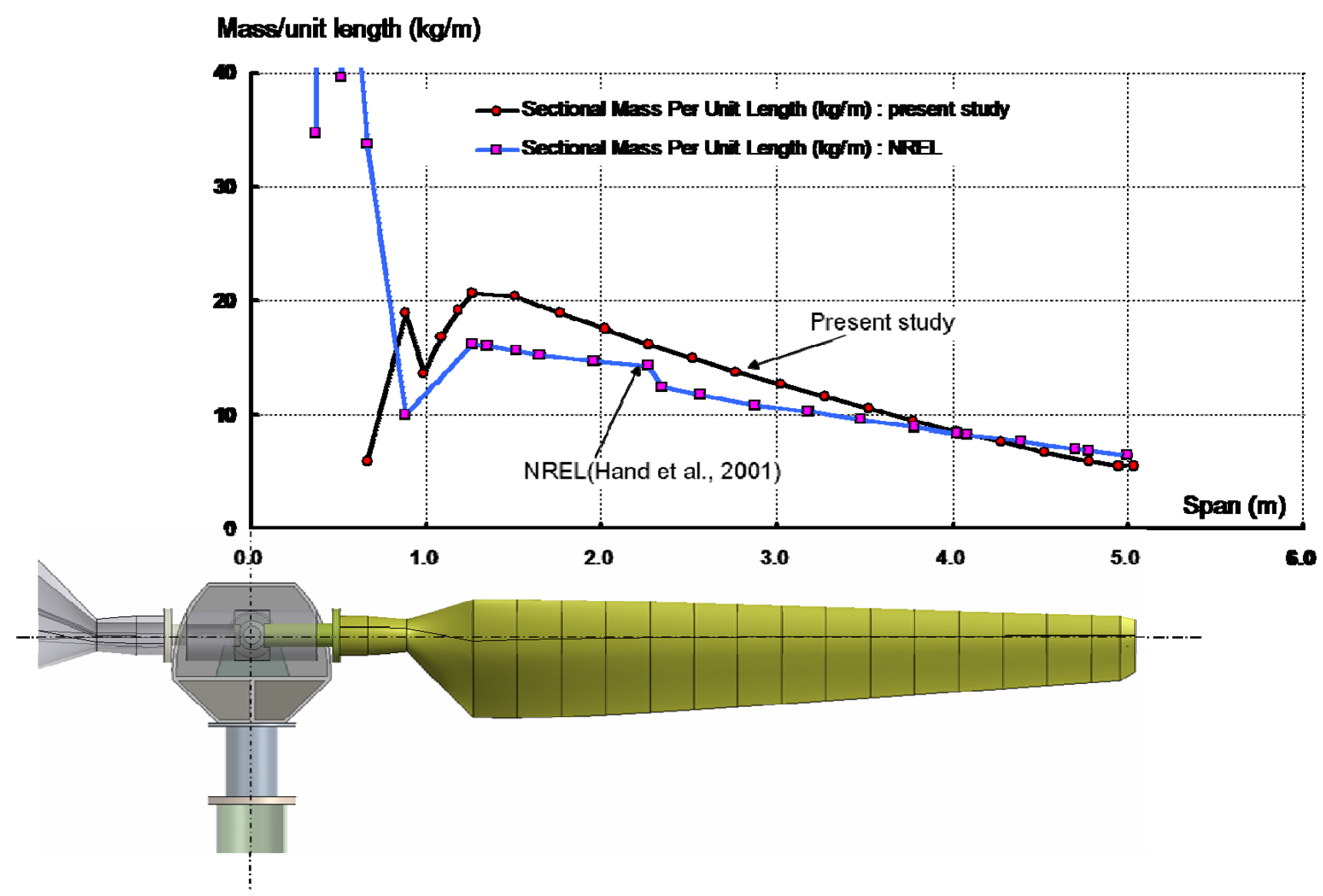

Fig. 6 Mass/unit (kg/m) distribution 


\section{Accumulative Mass (kg)}

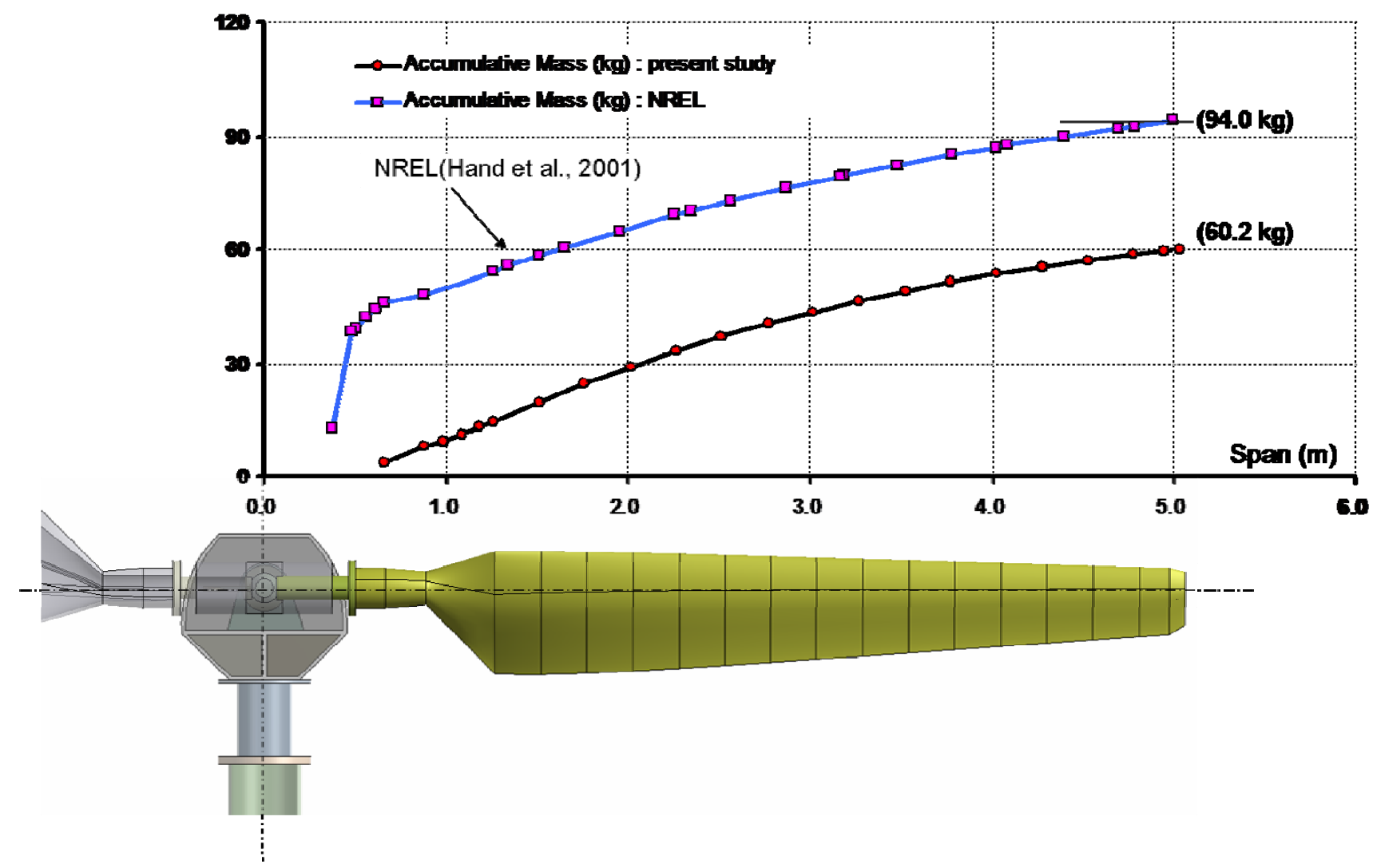

Fig. 7 Accumulative mass (kg) 


\section{Axial stiffness (Nm)}
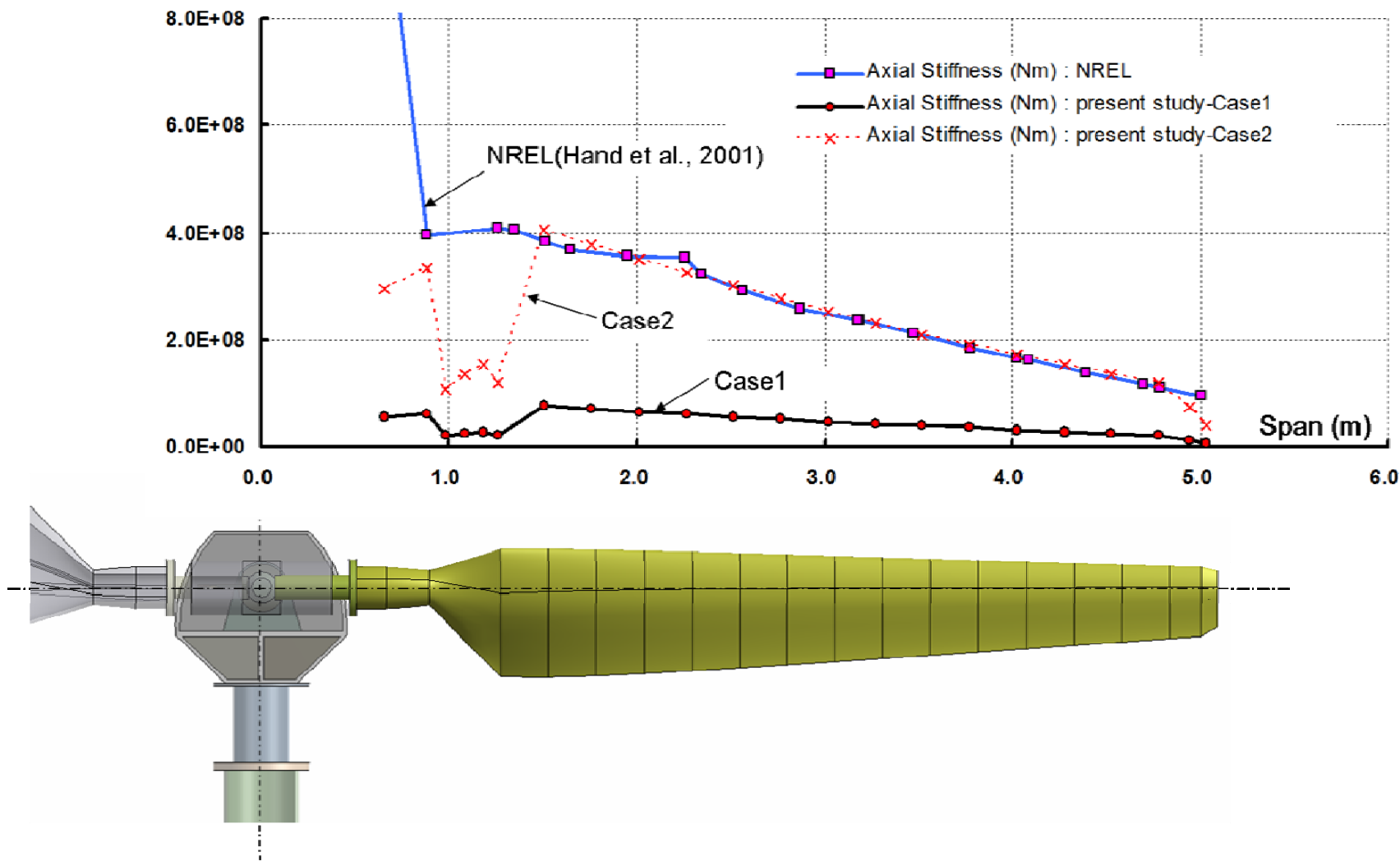

Fig.8 Axial stiffness (Nm) distribution for Case1 and Case2 

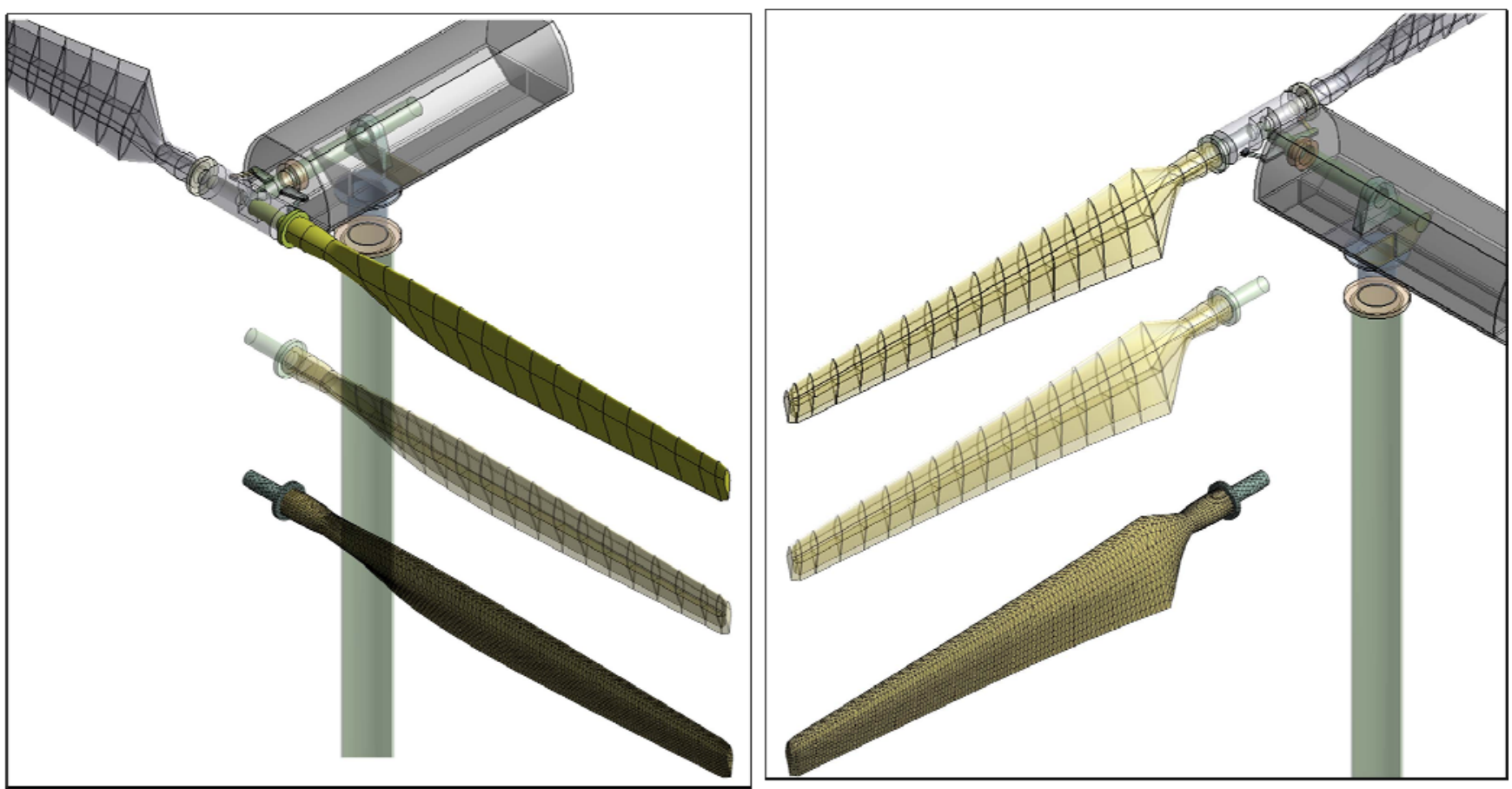

$<$ Fig. 9> Geometry and mesh model of blade (Mesh type2 in Fig. 10) 


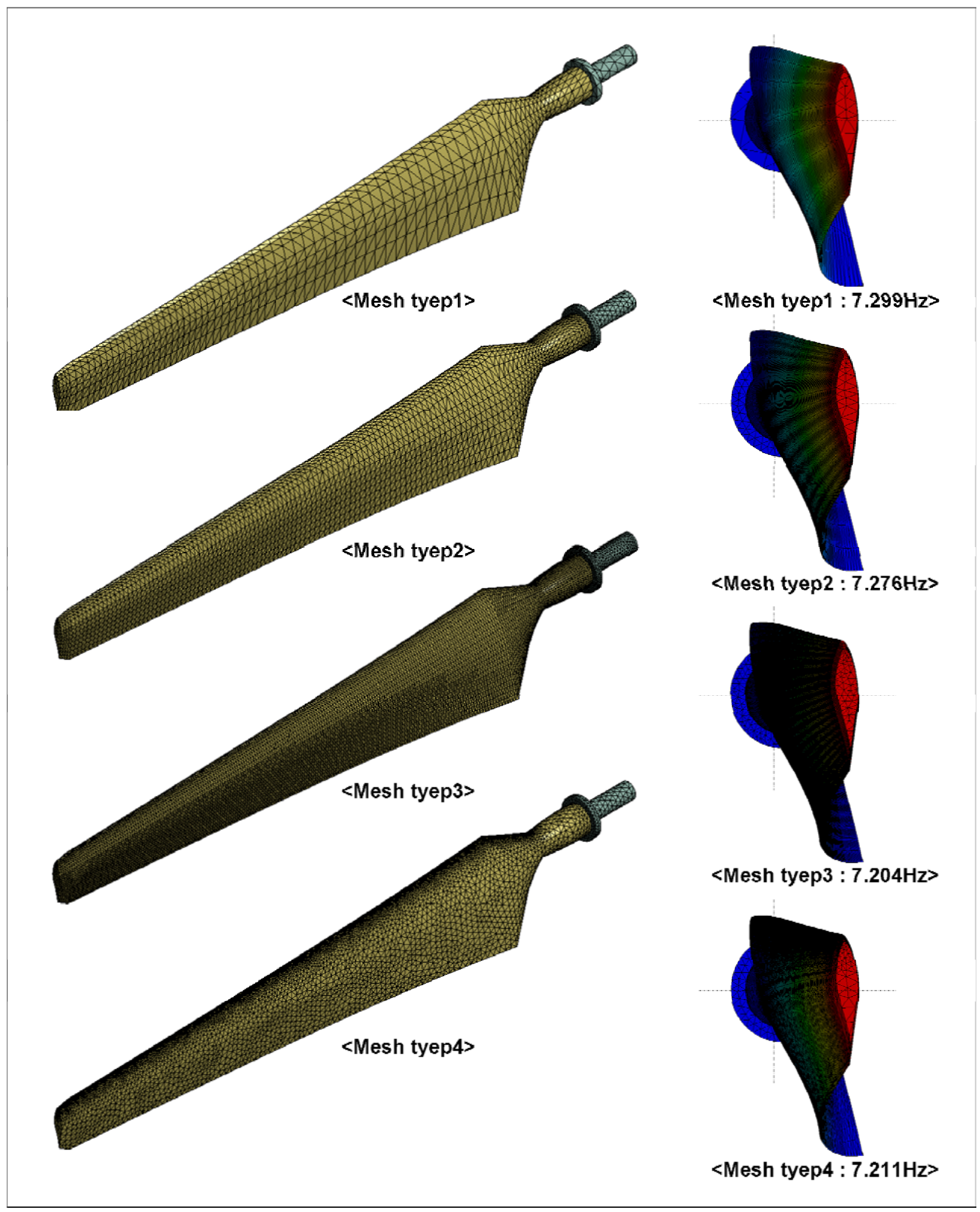

$<$ Fig. 10> Mesh quality test: Case1, 1st mode shape 


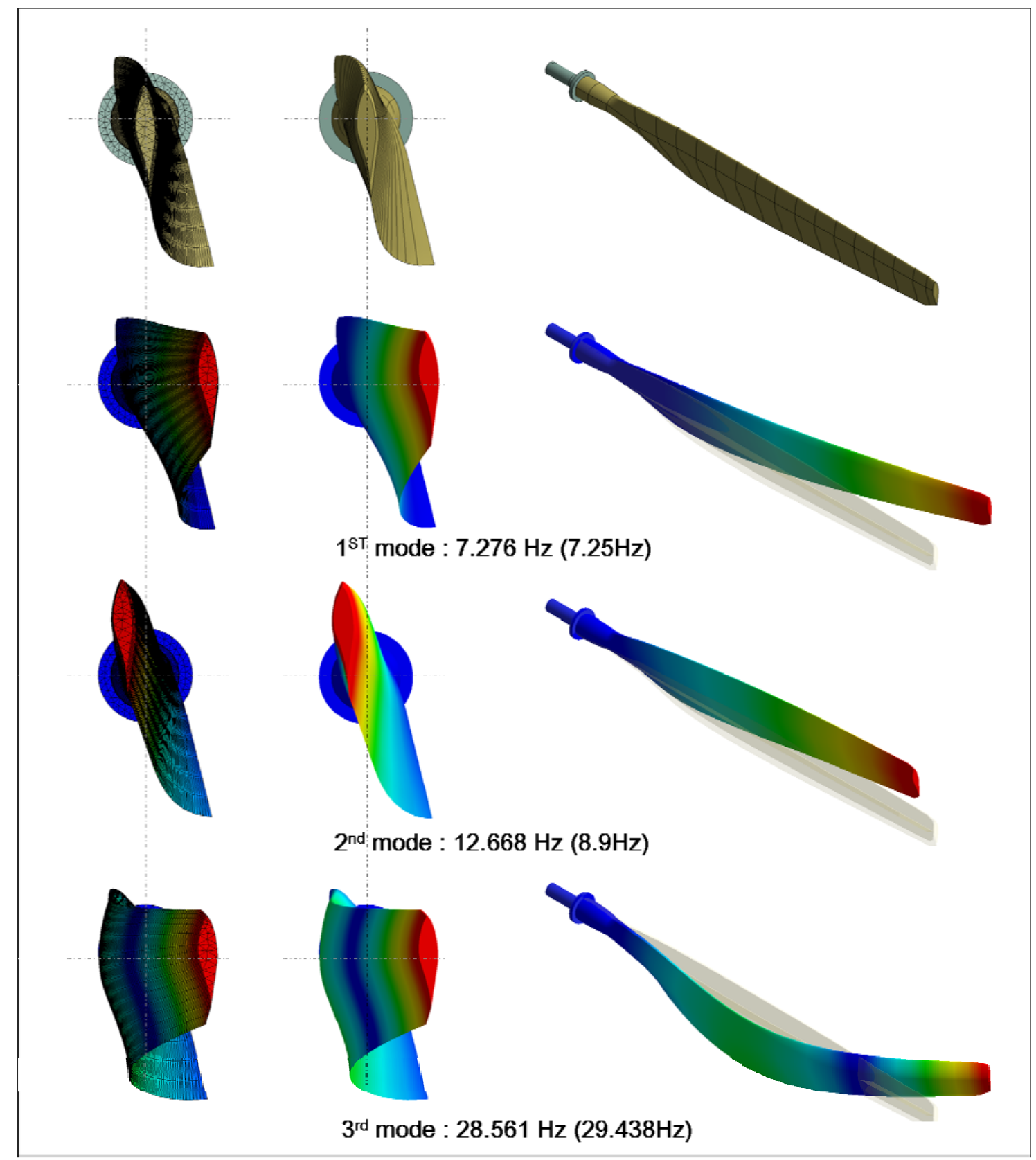

$<$ Fig. 11 $>$ Natural frequencies of blade (Mesh type2): Case1 


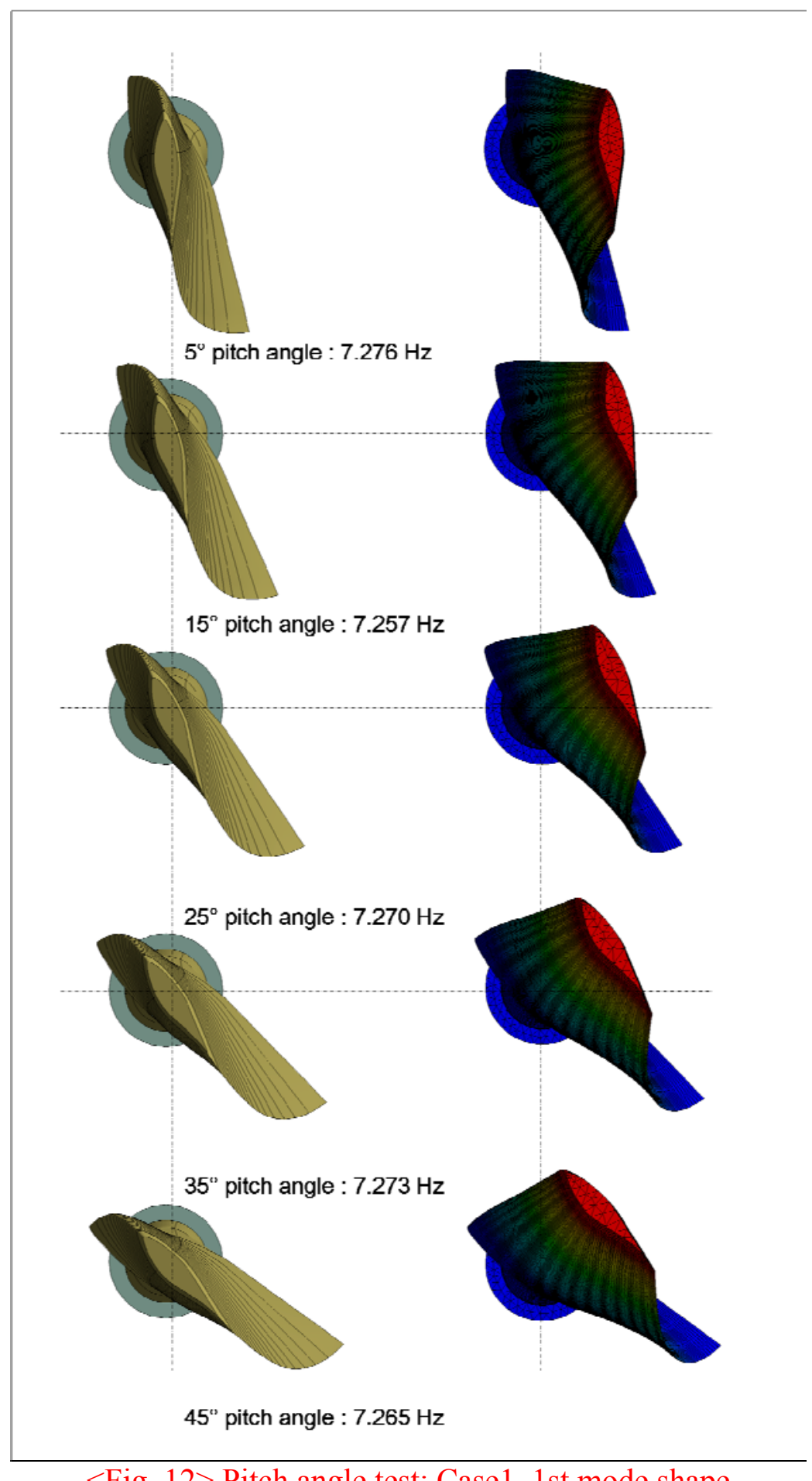

$<$ Fig. 12> Pitch angle test: Case1, 1st mode shape 


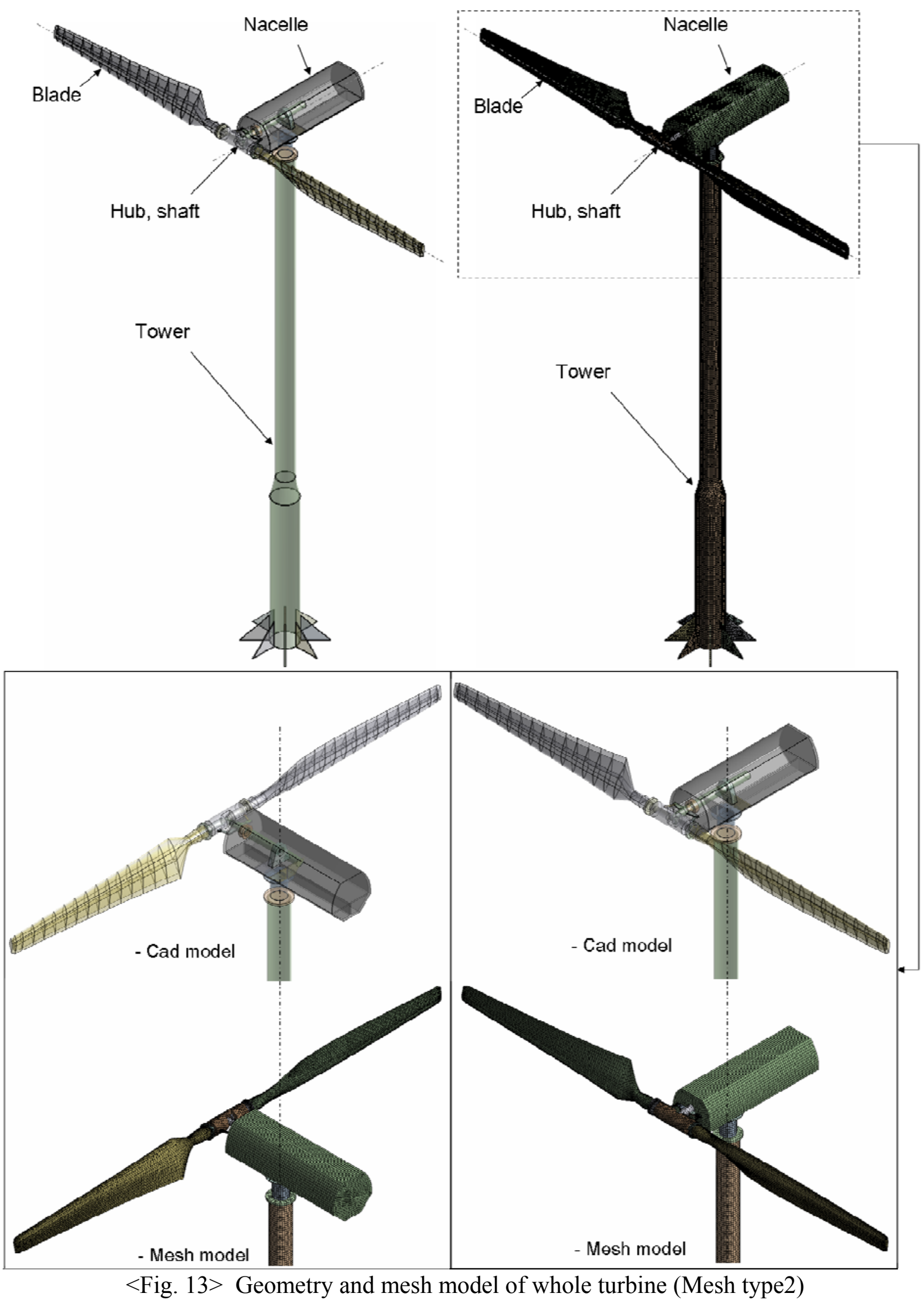




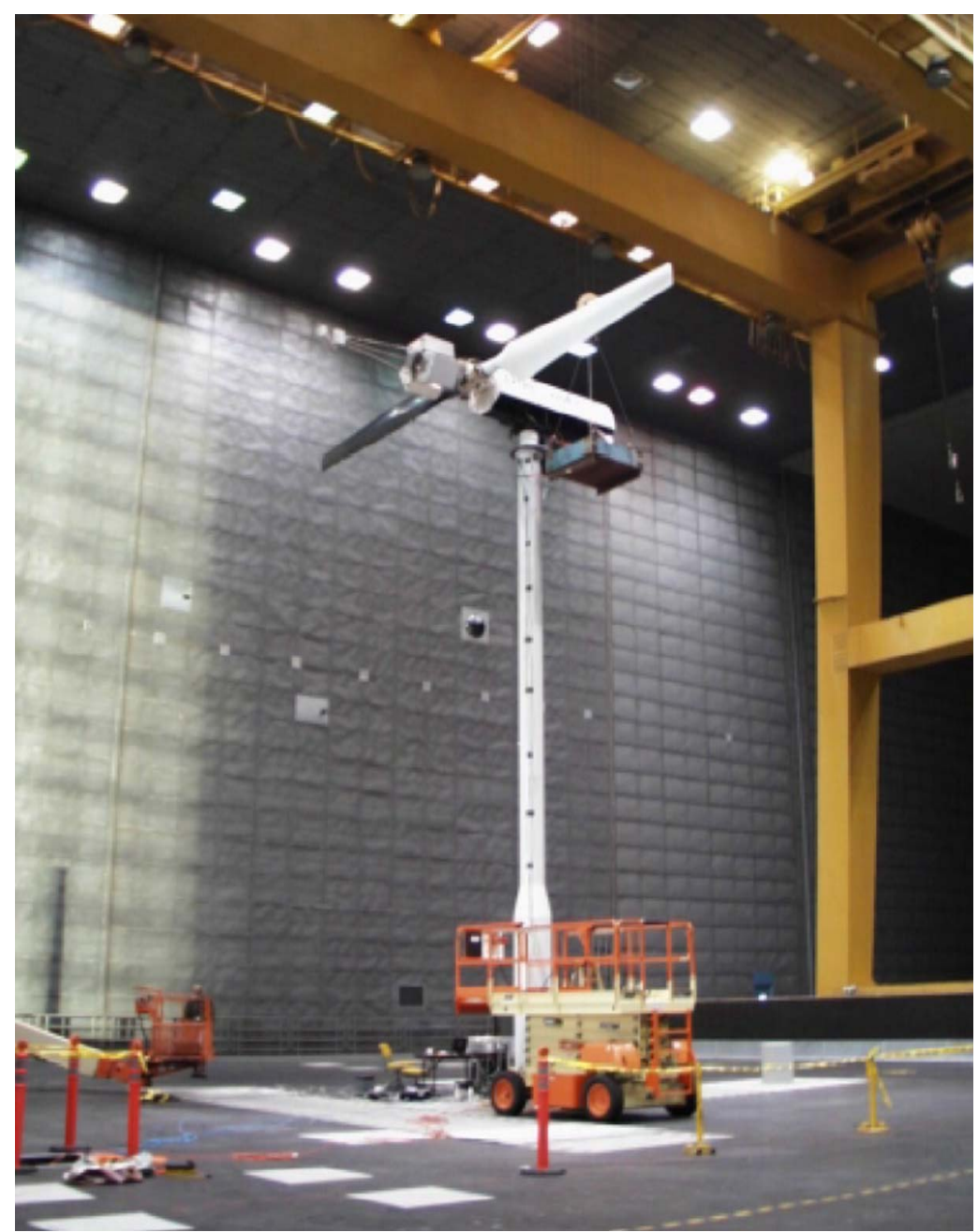

$<$ Fig. 14 $>$ Photo experiment : steel reaction mass suspended from gantry crane [3] 


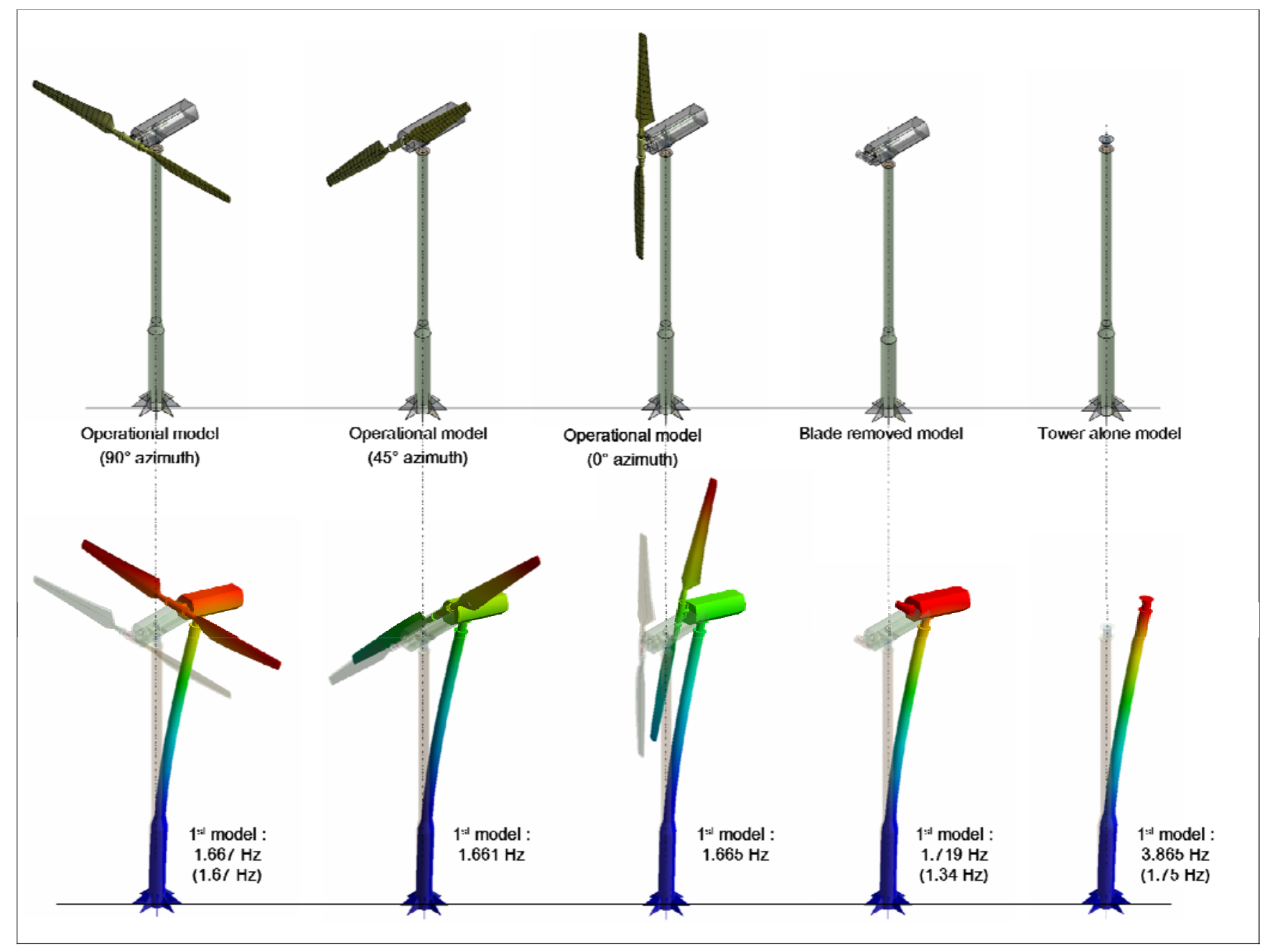

$<$ Fig. 15> Geometries and natural frequencies of various turbine configurations with case 1 material property (scale 100) 


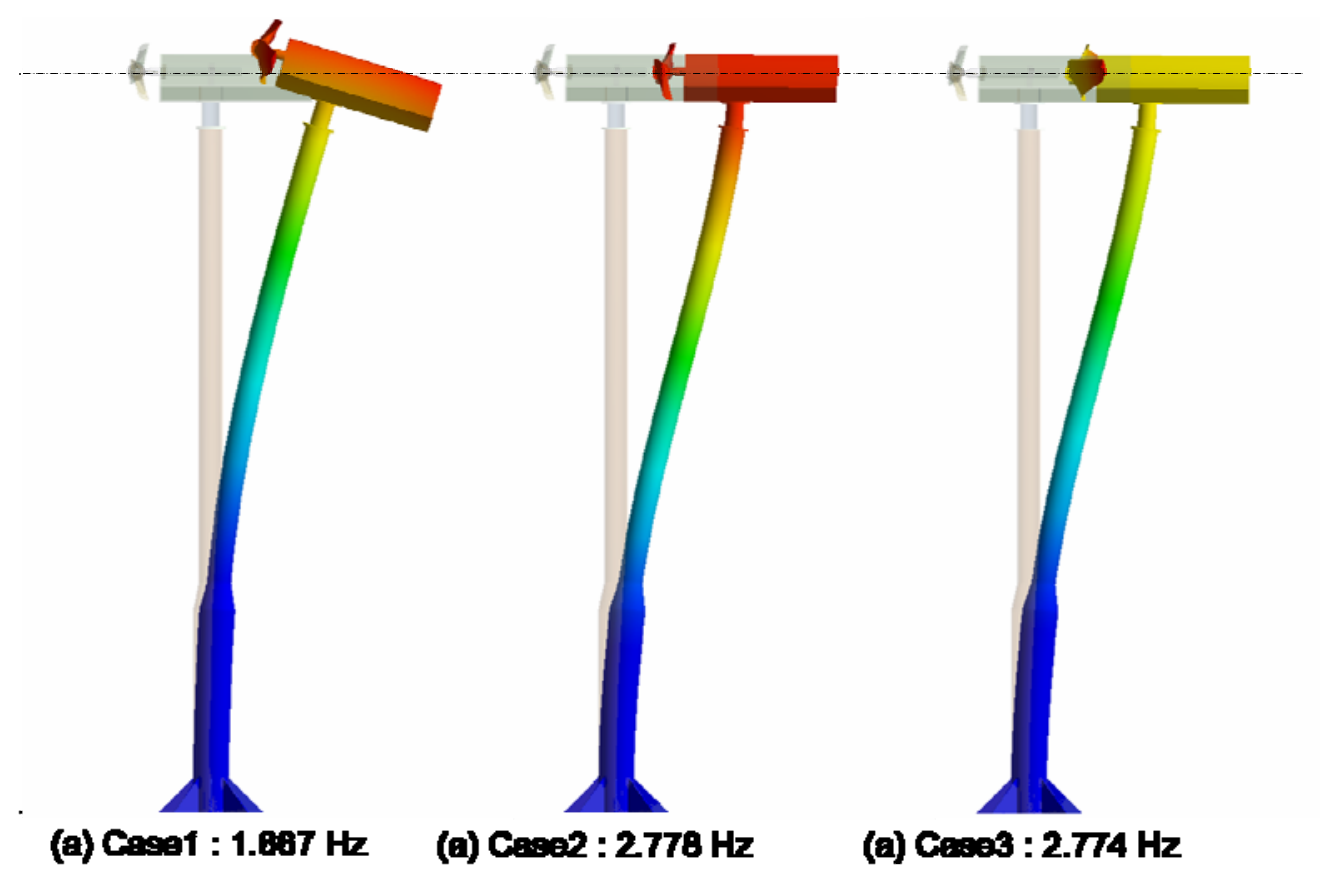

$<$ Fig. 16> Natural frequencies of various material properties: 90degree azimuth angle (scale 100) 


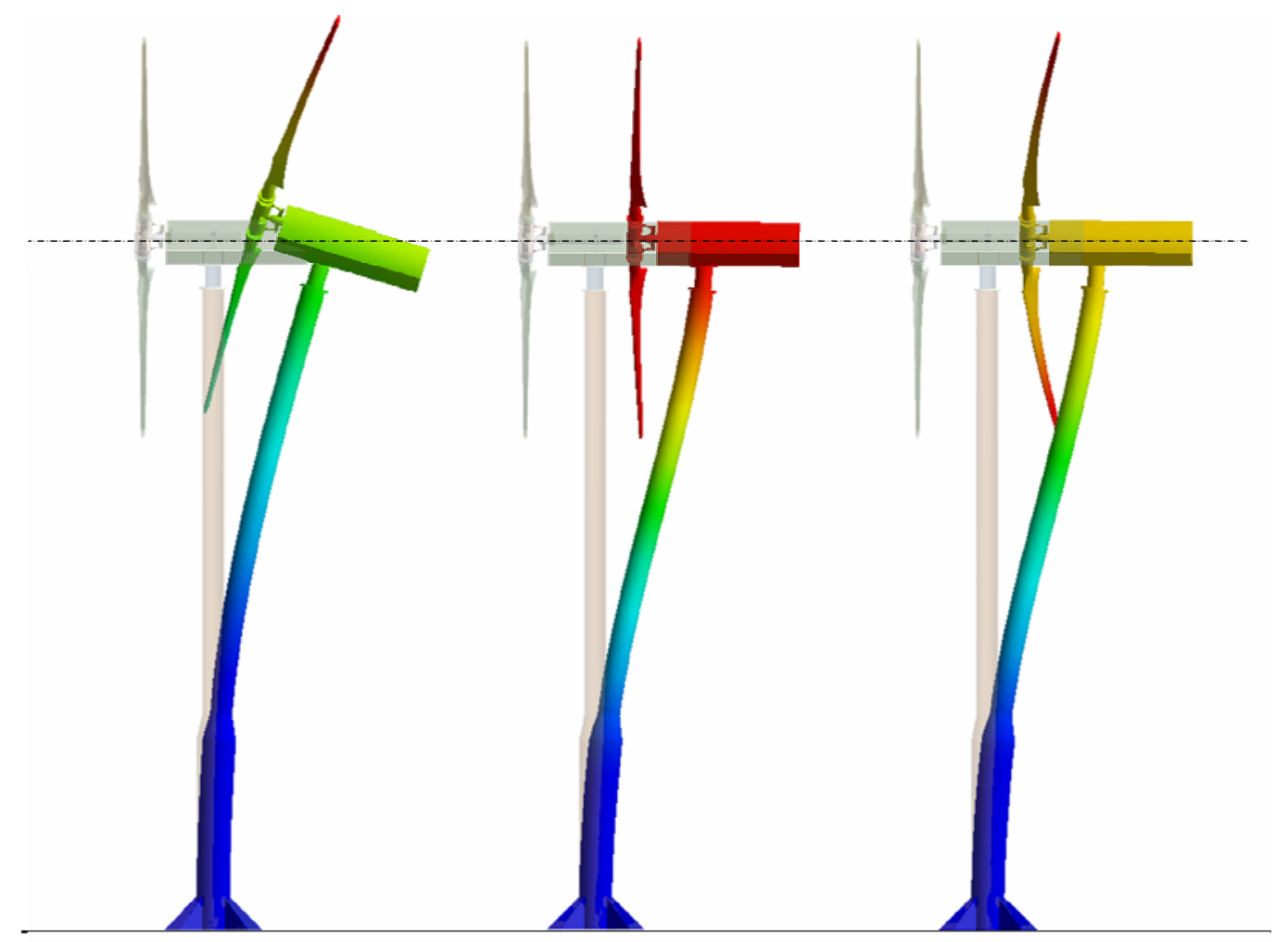

(A) Cose1: $1.661 \mathrm{~Hz} \quad$ (a) $\operatorname{Cesea2:2771\mathrm {Hz}}$

(a) Case3 : $2.767 \mathrm{~Hz}$

$<$ Fig. 17> Natural frequencies of various material properties: 45degree azimuth angle (scale 100) 


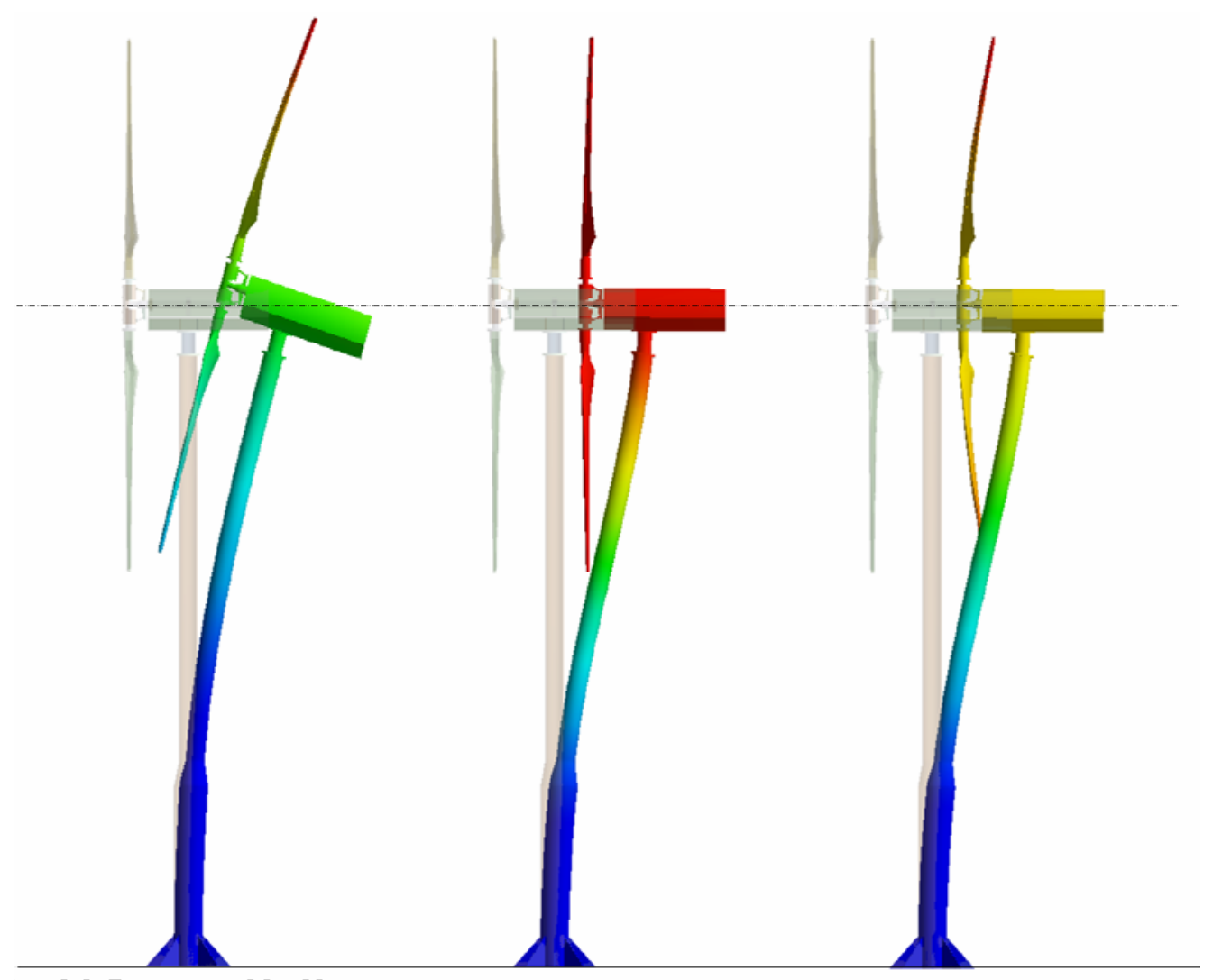

$\begin{array}{lll}\text { (a) Case1 : } 1.695 \mathrm{~Hz} & \text { (a) Case2 : } 2783 \mathrm{~Hz} & \text { (a) Cases : } 2779 \mathrm{~Hz}\end{array}$

$<$ Fig. 18> Natural frequencies of various material properties: 0degree azimuth angle (scale 100) 

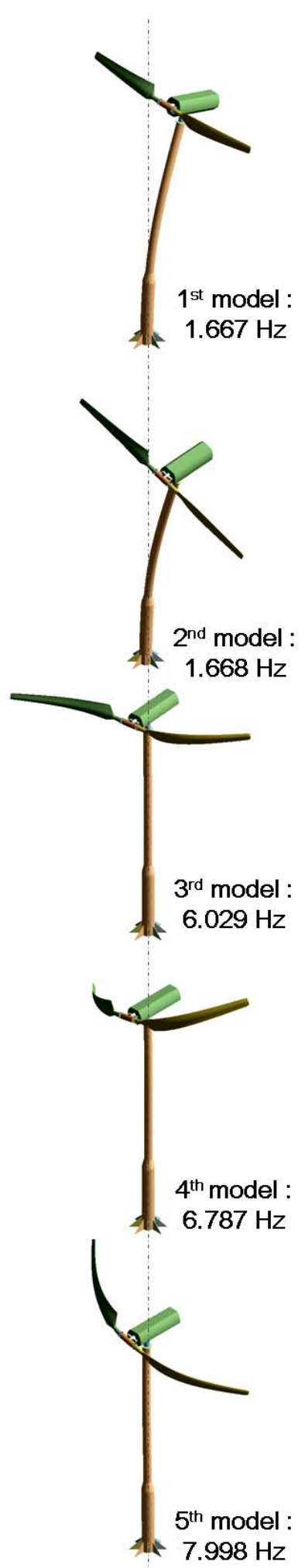
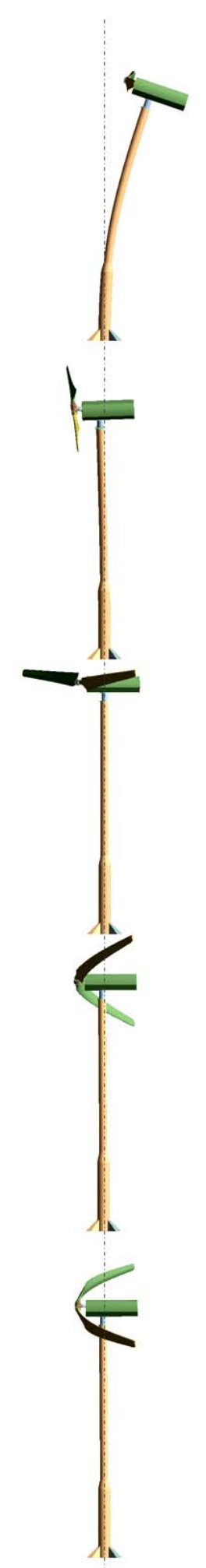
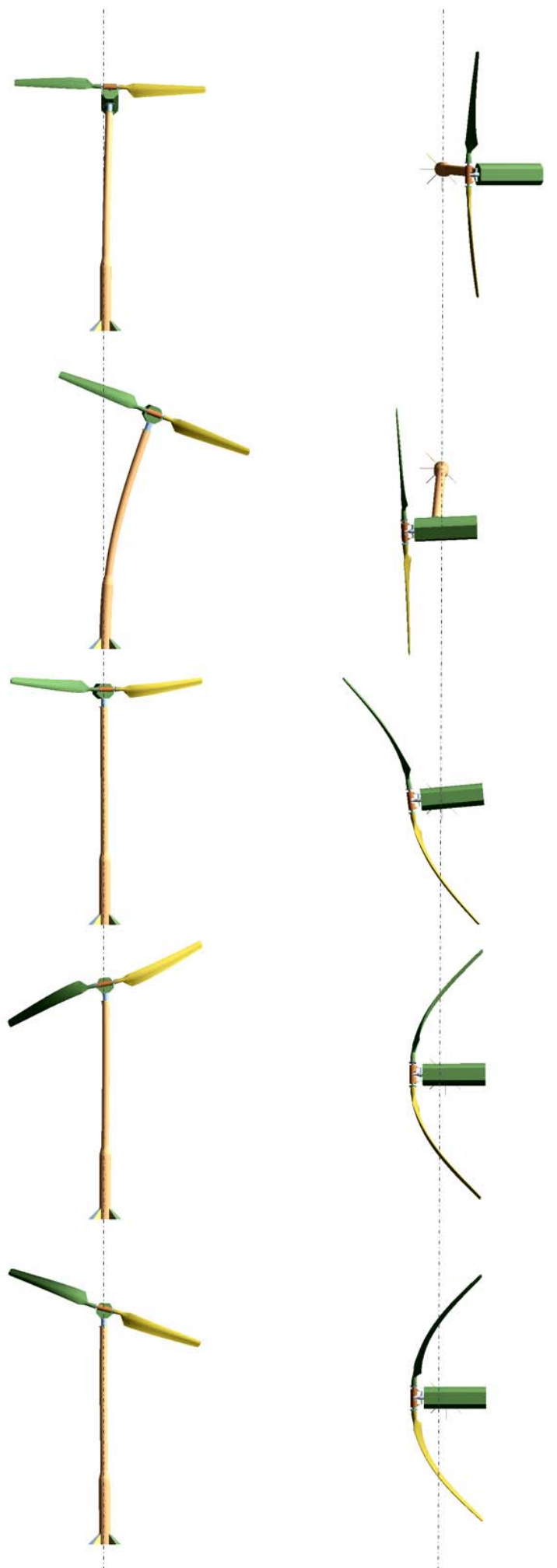

$<$ Fig. 19 $>$ Eigen modes of operation model with 90degree azimuth angle and case 1 material property (scale 100) 


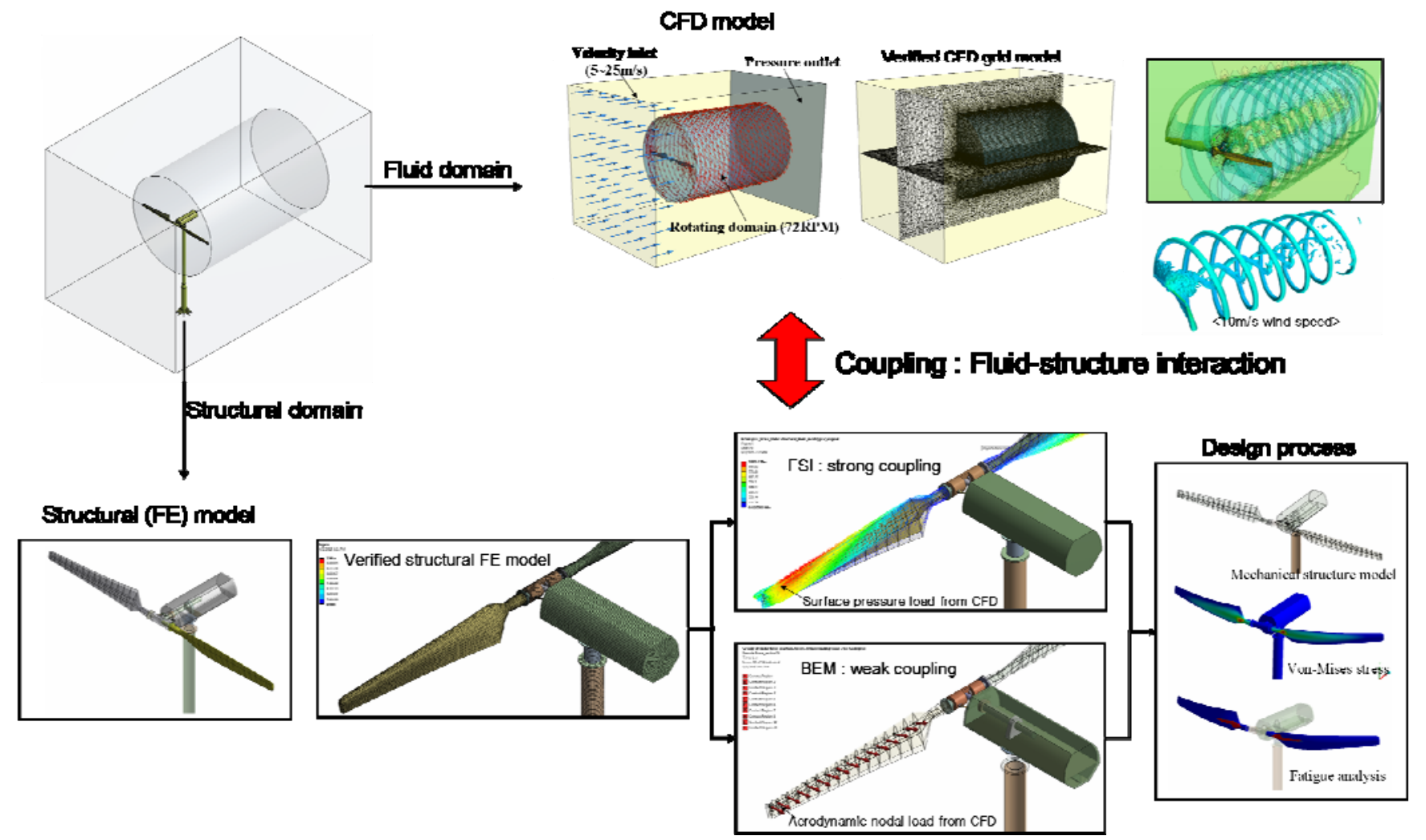

(a) Fluid-structure interaction by using fluid and structure model

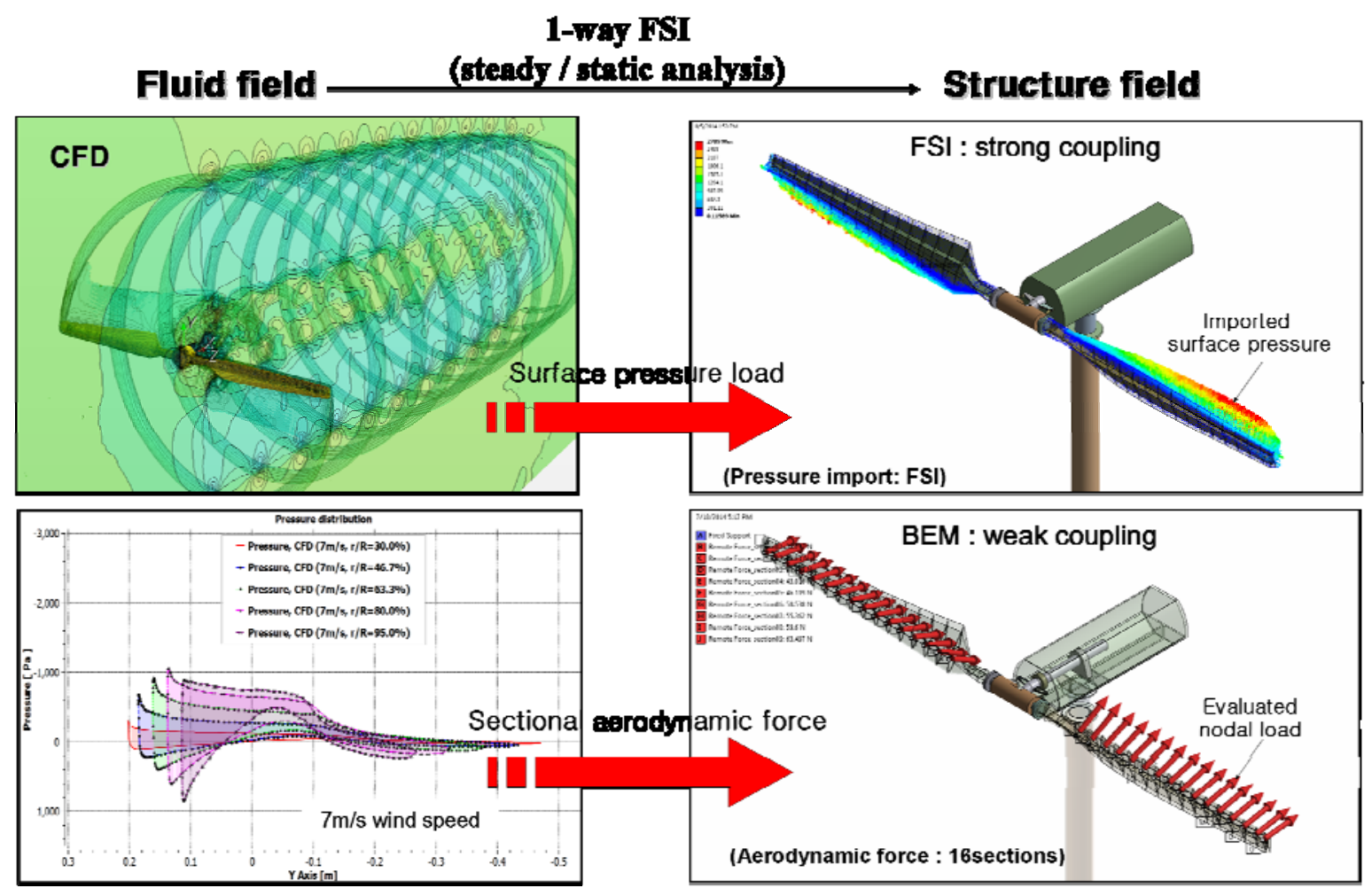

(b) 1-way fluid-structure interaction analysis for strong and weak coupling: FSI and BEM 


\section{2-way FSI}

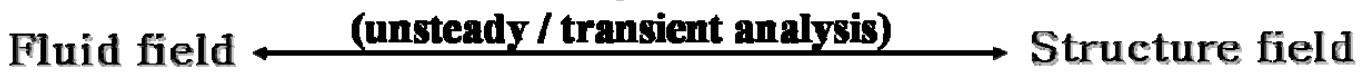
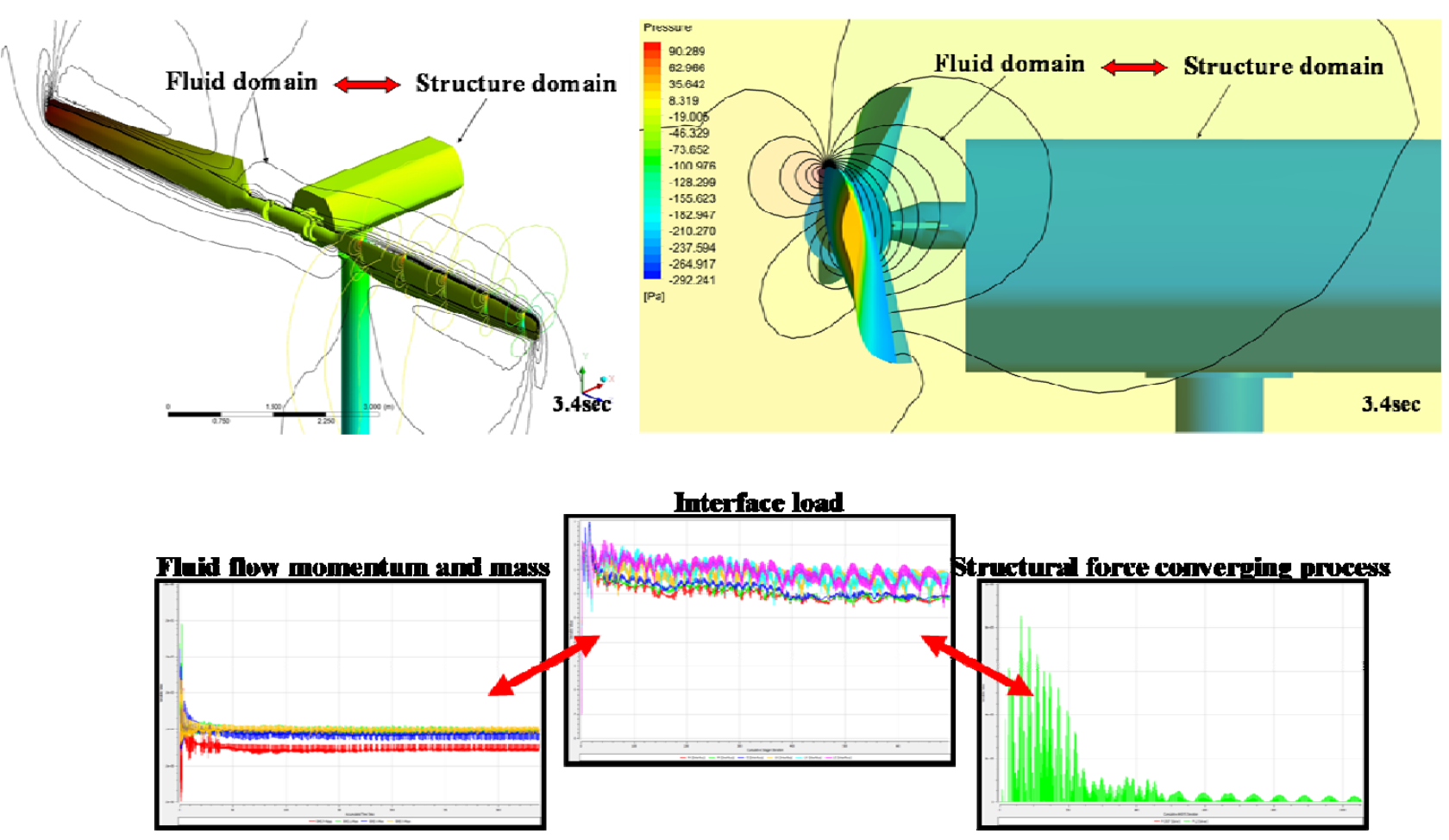

(c) 2-way fluid-structure interaction: strong coupling by using interface

$<$ Fig. 20> Concept and process of fluid structure interaction for NREL Phase VI wind turbine 


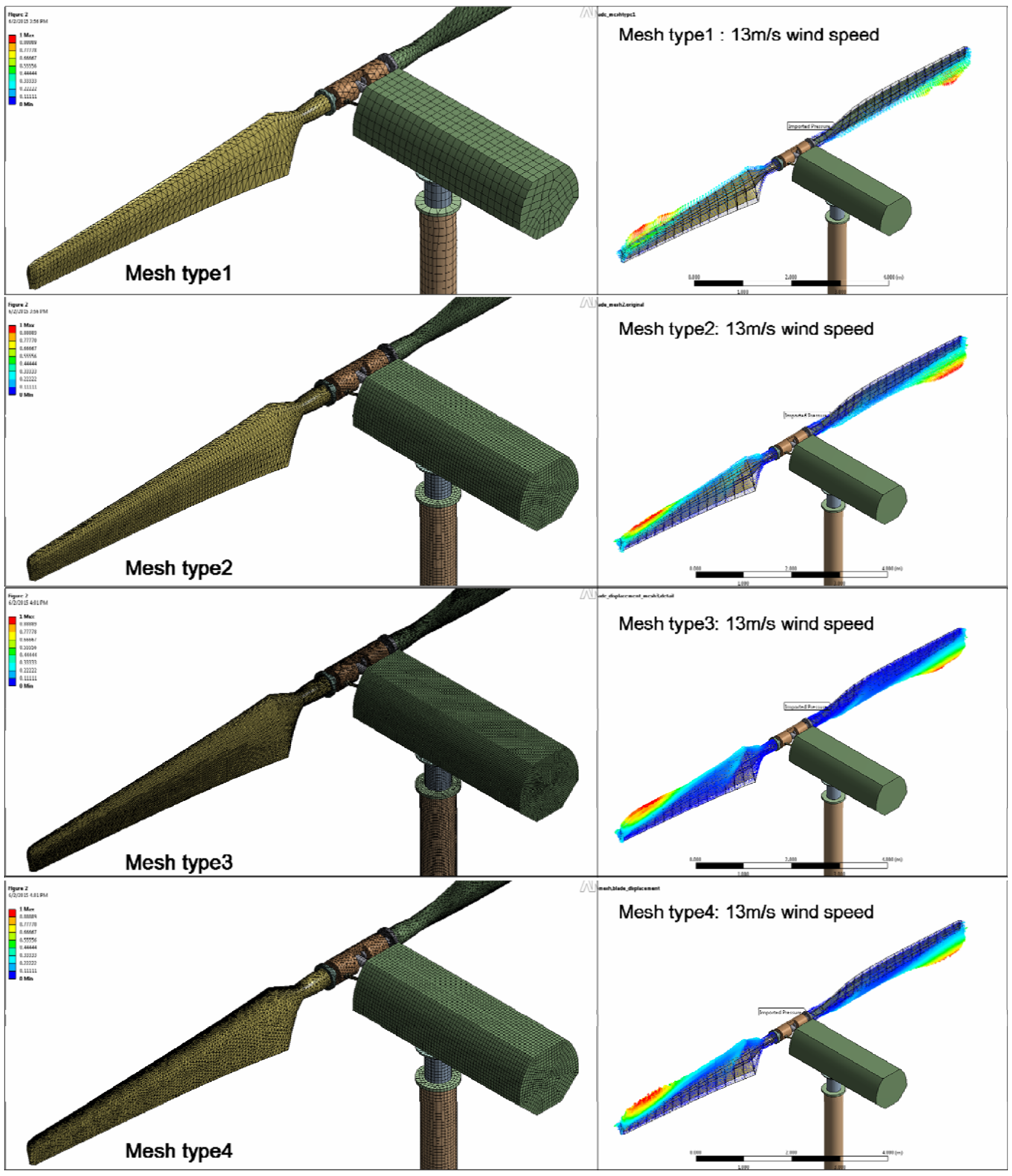

(a) Mesh types and imported pressure load 


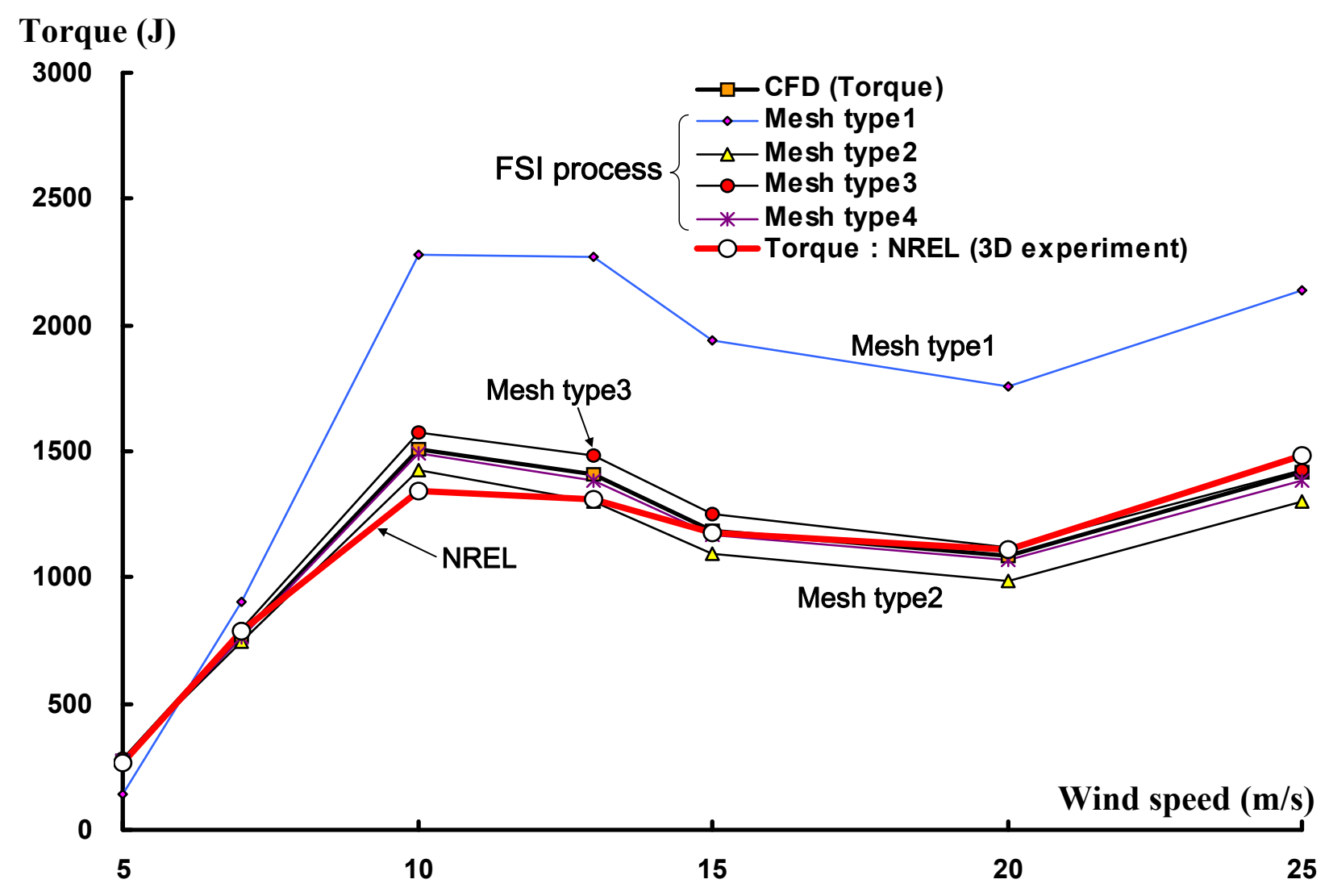

(b) The accuracy of mesh types for 1-way FSI analysis from torque value evaluation

$<$ Fig. 21>1-way FSI analysis for each mesh types 


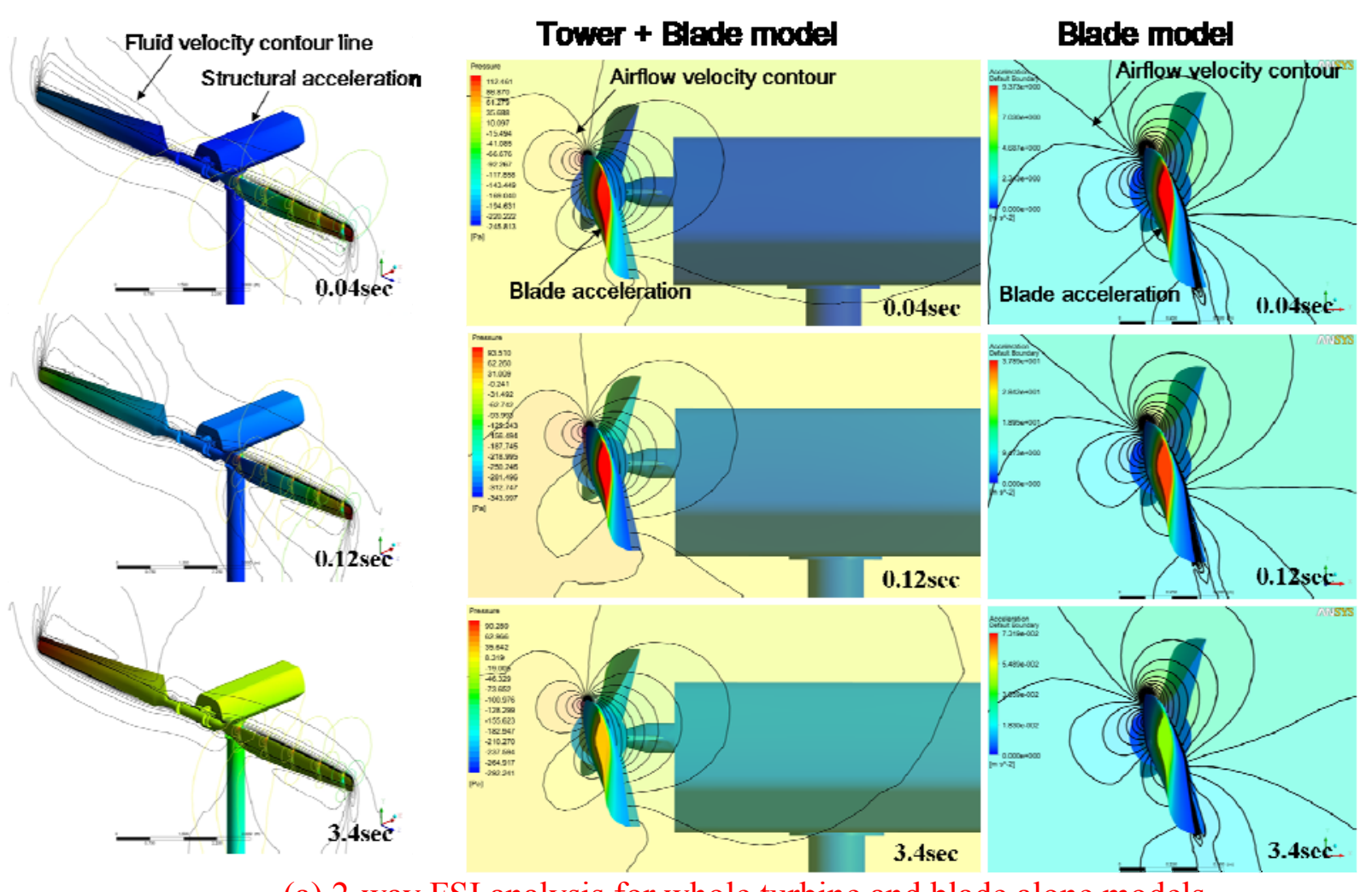

(a) 2-way FSI analysis for whole turbine and blade alone models

\section{- Blade vibretlon without tower}

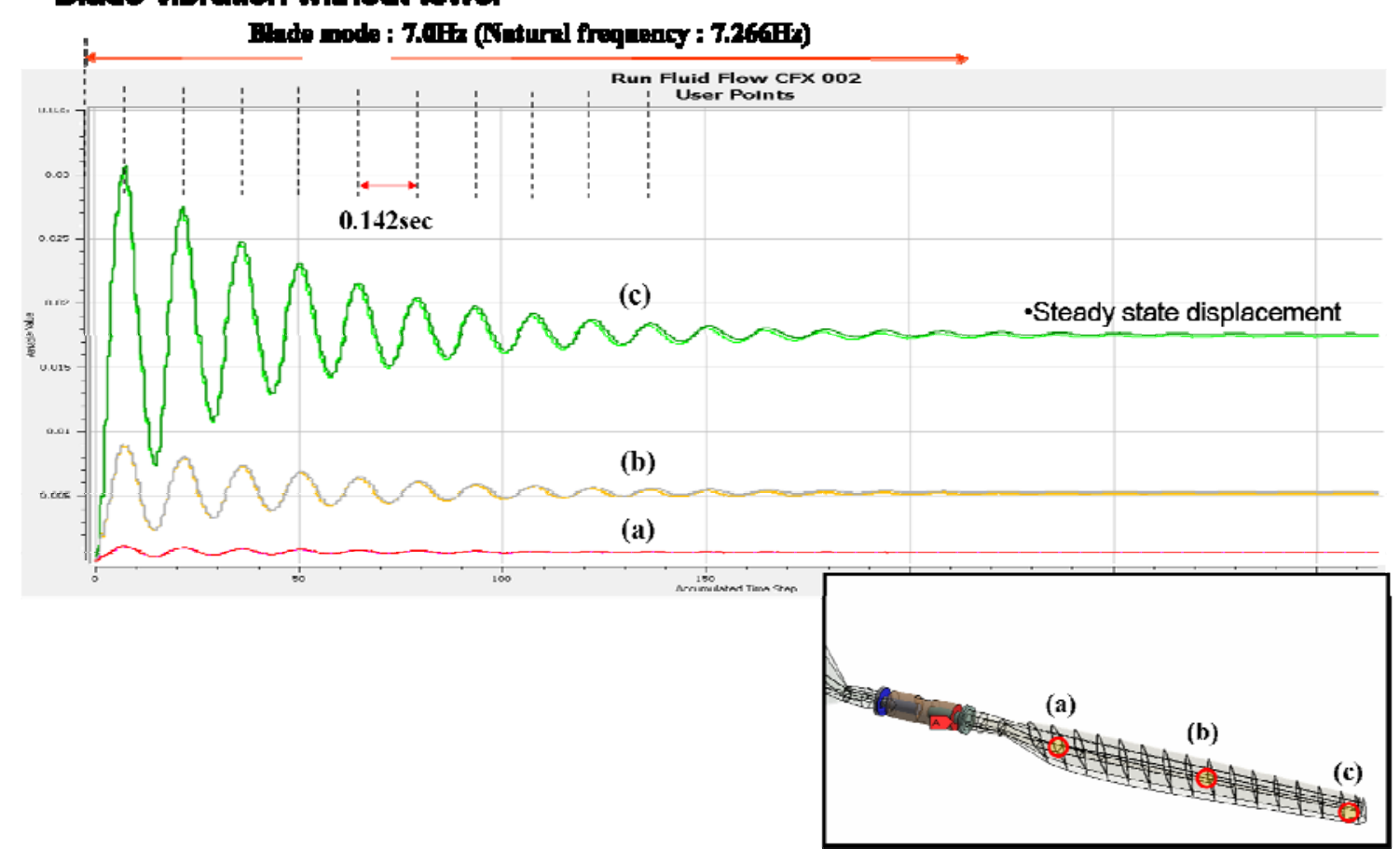

(b) Vibration of blade alone model: 2-way FSI analysis 


\section{- Blade + Tower vibration}

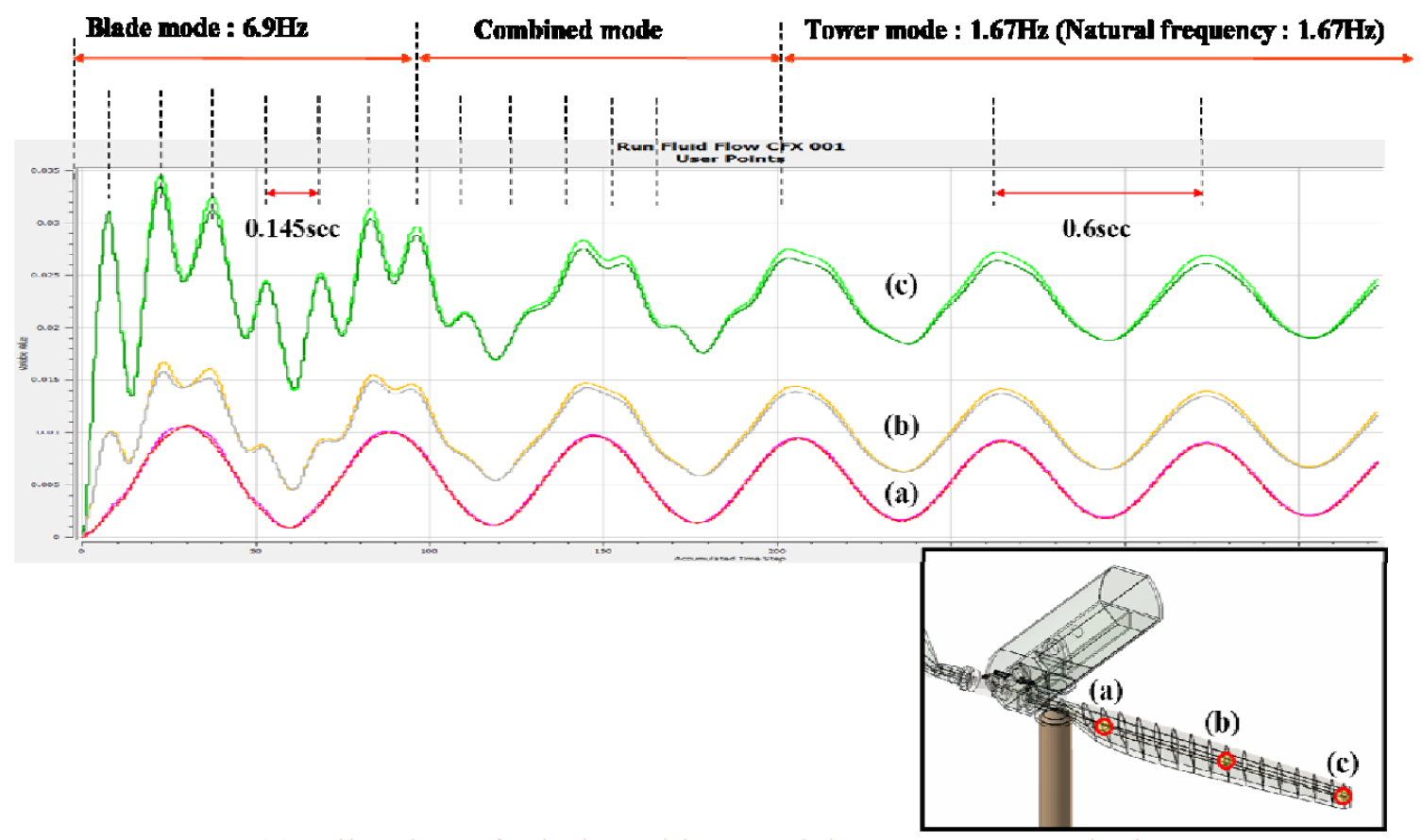

(c) Vibration of whole turbine model: 2-way FSI analysis

$<$ Fig. 22 $>$ 2-way FSI analysis for whole turbine and blade alone model 


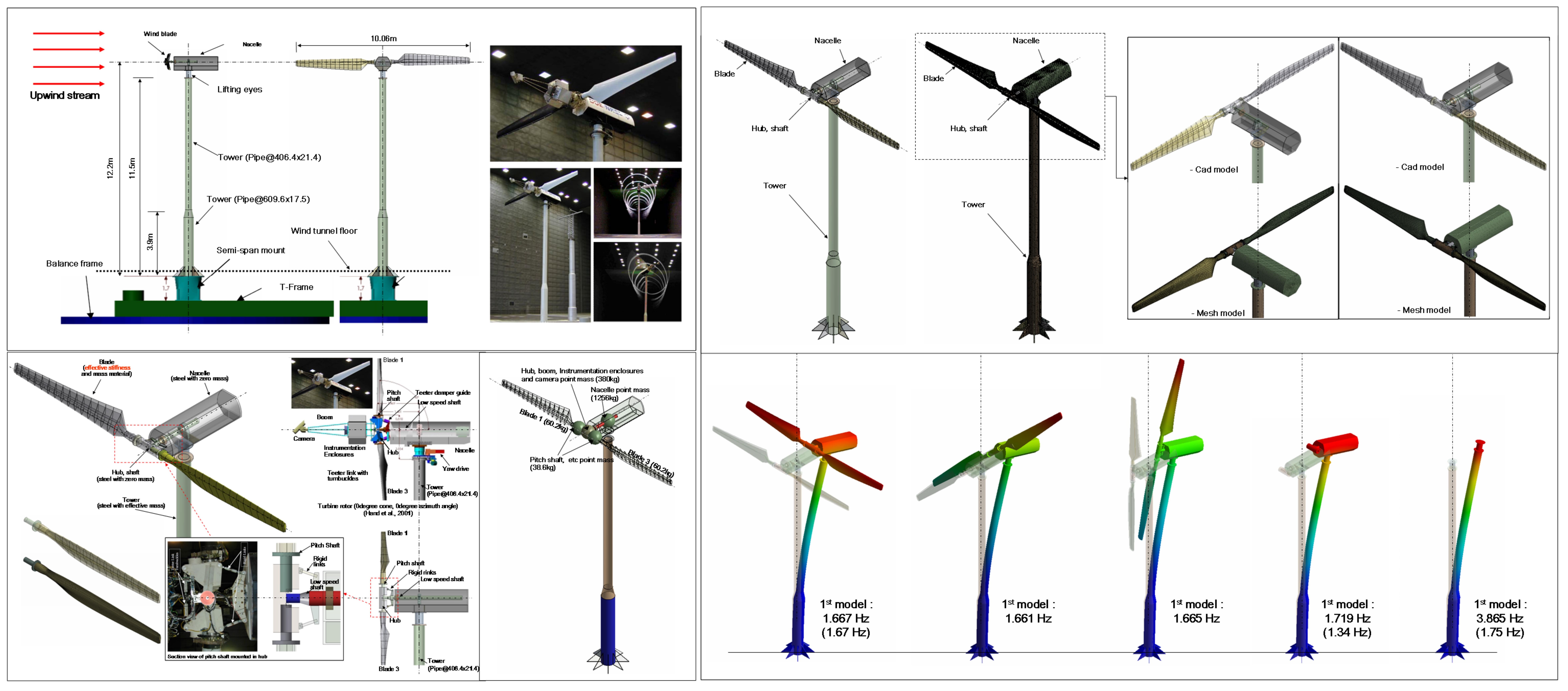

